REVISTA DE DERECHO UNED, NÚM. 12, 2013

\title{
REPARTO DE COMPETENCIAS MEDIOAMBIENTALES ENTRE LA UNIÓN EUROPEA Y LOS ESTADOS MIEMBROS
}

\section{SHARING OF ENVIRONMENTAL COMPETENCES BETWEEN THE EUROPEAN UNION AND THE MEMBER STATES}

\author{
Alicia de los Ángeles Roda MuÑoz* \\ Doctorando en el Departamento de Derecho Internacional Público \\ Universidad Nacional de Educación a Distancia
}

Resumen: Cuando se firmaron los Tratados de Roma de la Comunidad Económica Europea (CEE) en marzo de 1957, en la CEE no existía una preocupación apremiante por la cuestión medioambiental, por ello, los tratados originales no contenían provisión concreta relativa a la protección del medio ambiente, y tampoco se había atribuido una competencia en esta materia a las instituciones comunitarias. No obstante, el Tratado Constitutivo de la Comunidad Económica del Carbón y del Acero (TCECA) de 1952, ya había tomado en consideración la investigación de ciertos aspectos de la contaminación causada por las industrias del carbón y del acero. Y posteriormente, el Tratado Constitutivo de la Comunidad Europea de la Energía Atómica (TCEEA o EURATOM) de 1957 introdujo, por primera vez, algunas normas básicas de índices de radiación ionizante. Afortunadamente la Comunidad Europea CE fue evolu-

* En 2009-2010 Profesora Docente Investigadora en el Departamento de D.I.Púb. de la UNED en Madrid. El artículo que aquí se presenta está basado en un capítulo de la tesina titulada "La importancia de la política comunitaria de medio ambiente y su aplicación en el interior de la Unión Europea». Actualmente, A. Roda trabaja en su Tesis dirigida por la Directora del Departamento de Derecho Internacional Público de la UNED, Dra. D. ${ }^{a}$ Fanny Castro-Rial Garrone, y como codirector, el Dr. D. Eduardo Trillo de Martín-Pinillos. 
cionando rápidamente y en los años 70 la CE comenzó a desarrollar su primera legislación en este área, principalmente en forma de «directivas», iniciando así un camino imparable. De hecho, poseemos el cuerpo normativo ambiental más extenso del mundo y los Estados miembros (EEMM) basan más del 80\% de sus normativas nacionales medioambientales en la legislación comunitaria.

El presente artículo hace un recorrido por «las competencias» que tienen atribuidas las instituciones de la Unión Europea (UE) por sus EEMM para conseguir los fines medioambientales que tienen en común, asimismo, se compara el grado de atribución de la competencia medioambiental a través de las reformas de los Tratados comunitarios.

Abstract: When the Treaties of Rome of the European Economic Community (EEC) were signed in Rome in March 1957, it did not exist an imminent concern towards the environmental issue, for that reason, the original Treaties did not contain either a specific provision relative to environmental protection, or a recognized competence of this matter attributed to the communitarian institutions. However, the Treaty establishing the European Community of Coal and Steal (TECSC), in 1952, had already taken into account the investigation of some aspects of the contamination caused by the industries of coal and steel. And after, the Treaty establishing the European Atomic Energy Community (TEAEC or EURATOM) in 1957, included, for the very first time, some basic standards of ionizing radiation. Fortunately, the European Community (EC) was progressing quickly on environmental contents. In 70's decade, the EC began to develop its first legislation in this area, mainly in form of «directives», hence undertaking an unstoppable way. In fact, we possess the most extensive environmental normative body of the world and more of $80 \%$ of the environmental national norms of the Member States (MS) are based on the communitarian legislation.

The present article mainly makes a route through «the competences», which have been conferred upon the European Union (EU) by its MS in order to attain environmental objectives they have in common. In addition, it is compared the degree of attribution of the environmental competence through the renovation of communitarian Treaties.

Palabras clave: Reparto de competencias medioambientales, Unión Europea, Estados Miembros. 
Keywords: Sharing of environmental competences, European Union, Member States.

Recepción original: 26/04/2013

Aceptación original: 29/04/2013

Sumario: I. El inicio de las Comunidades Europeas y su primera legislación medioambiental; II. Modos de atribución de competencias a las CEE (actualmente UE) por parte de los Estados miembros. La competencia ambiental; III. El Acta Única Europea, El Tratado de Niza y el Tratado de Lisboa: sus contribuciones a la legislación ambiental comunitaria y su influencia en la atribución de competencias en medio ambiente; IV Consolidación de las funciones de los Parlamentos nacionales en el Tratado de Lisboa; V. Consideraciones finales.

\section{EL INICIO DE LAS COMUNIDADES EUROPEAS Y SU PRIMERA LEGISLACIÓN MEDIOAMBIENTAL}

"La integración europea ha sido una constante del pensamiento europeo y ello también durante los siglos previos al siglo $X X{ }^{1}$.

Todas las propuestas europeístas, desde la Edad Media hasta la postguerra de la Segunda Guerra Mundial (IIGM), han sido aportadas por pensadores y políticos que han tenido afortunadamente un fundamento común: «la identidad cultural de los Estados europeos».

Las bases de la nueva organización de las relaciones internacionales mundiales comenzaron a perfilarse por las naciones aliadas a lo largo del desarrollo del conflicto de la IIGM. Desde antes del final de la guerra y a pesar de los compromisos alcanzados en las Conferencias de Yalta y Postdam (1944-1945), se va vislumbrando la formación de dos bloques entre los aliados: uno occidental, liderado por norteamericanos y británicos, y otro oriental, bajo la influencia soviética.

Apenas terminada la II Guerra Mundial, la tensión clara y cada vez más intensa entre el Este y el Oeste y el fracaso de la Conferencia de Moscú en abril de 1947 sobre la cuestión alemana, había convencido a los occidentales de que la Unión de Repúblicas Soviéticas iba a convertirse en un peligro inmediato para las democracias occiden-

1 Mangas Martín, A. y LiÑán Nogueras, D.J.: Instituciones y Derecho de la Unión Europea, Madrid. Editorial Tecnos (5. a ed. reimpresión), 2006. Capítulo I «El proceso histórico de la UE», pág. 33. 
tales. Ello configurará la política de la postguerra y determinará la división de Europa y del mundo porque sobre la Europa arrasada, las dos superpotencias -EEUU y la URSS- se repartirían las zonas de influencia. A la vez, las dos superpotencias se van a ver dirigidas hacia el antagonismo y una creciente desconfianza entre Truman y Stalin, sobre todo, desde que falleciera el presidente americano Roosevelt antes del final de la contienda. Las declaraciones encontradas entre uno y otro fueron la constante en esos años (1946-1949) ${ }^{2}$.

En el contexto posbelicista de la Segunda Guerra Mundial (IIGM), se reunió en La Haya del 7 al 11 de mayo de 1948 el Comité de Coordinación de Movimientos para la Unidad Europea. Con posterioridad al congreso decidieron federarse las distintas asociaciones fundiéndose en el Movimiento Europeo ${ }^{3}$.

En la primavera de 1950, el 9 de mayo, el Ministro de Asuntos Exteriores francés Robert Schuman leyó ante la prensa una declaración escrita por él, Jean Monnet, Paul-Henri Spaak y otros colaboradores, en la que proponía a los Estados europeos la creación de una Comunidad Europea del Carbón y del Acero (CECA). La CECA contenía una enorme carga simbólica, situando bajo una autoridad

2 De la TORRe Del Río, R. Notas del curso de Historia impartido por la Dra. Rosario de la Torre en el Máster Interuniversitario en RRII y Diplomacia 2007-08 de la Escuela Diplomática de Madrid. De la TORRE Del Río pertenece al cuadro de profesores de la Universidad Complutense de Madrid (UCM). Como nos destacara nuestra profesora: "El presidente estadunidense Truman tras retirar la ayuda económica a la Unión de Repúblicas Soviéticas (URSS) formuló su doctrina de "contención al comunismo", dando a conocer en 1947 el Plan Marshall de ayuda económica para la reconstrucción de Europa. En 1949 los Estados Unidos (EEUU) lideraron la creación de la Organización militar y de defensa para el bloque occidental (OTAN).

A lo largo de 1947 se había completado el dominio comunista sobre la Europa oriental. De hecho, las respuestas de Stalin a EEUU fueron las siguientes: en lo político, la creación de una zona de influencia constituida por la Europa Oriental (la República Democrática Alemana, que era la parte de Alemania que había quedado a su cargo; Polonia, Checoslovaquia, Hungría, Rumania, Bulgaria y Yugoslavia). En octubre de 1947 se creó el Kominform, que unía a los partidos comunistas de todo el mundo. El "golpe de Praga» de febrero de 1948, que aseguraba a los comunistas el poder sobre Checoslovaquia y, después, el bloqueo de los accesos a Berlín en junio de 1948, que preludiaba la división en dos alemanias, avivaron aún más la tensión. El primer Ministro británico, Churchill, fue el primero en advertir que "un telón de acero había dividido a Europa».

En lo económico, la contestación de la URSS fue la constitución del Consejo de Mutua Asistencia Económica (COMECON) en 1949, destinado a coordinar las economías de los países comunistas. En el ámbito defensivo, la respuesta fue el Pacto de Varsovia.»

Al respecto de esta temática, recomiendo por su indiscutible interés, el libro de los autores: Veiga, F., Da CAL, E.U. y Duarte, A; La Paz simulada. Una historia de la Guerra Fría, 1941-1991; Madrid. Ed. Alianza Editorial (Primera edición, 1996).

3 El Movimiento Europeo tuvo como presidentes, entre otros, a R. Schuman, W. Churchill, A. de Gasperi, P. Henri Spaak y K. Adenauer. 
común la producción del carbón y del acero de países que habían sido enemigos: Francia y la República Federal de Alemania Esta organización quedaba abierta a los demás países europeos, de hecho, otros cuatro países firmaron en París el 18 de abril el Tratado constitutivo de la CECA, entrando en vigor en julio de 1952 con sus seis socios fundadores: Bélgica, Francia, República Federal de Alemania, Italia, Luxemburgo y Holanda (Países Bajos).

La idea de avanzar hacia la unidad europea a través de la integración económica y social, impulsó también a los seis Estados miembros fundadores de la CECA a suscribir otros dos tratados, que fueron firmados el 25 de marzo de 1957 en Roma: El Tratado constitutivo de la Comunidad Europea de la Energía Atómica (TCEEA, también conocido por EURATOM)) y el Tratado constitutivo de la Comunidad Económica Europea (CEE), convirtiéndose la CEE en la precursora del proceso de construcción europea. El Tratado entró en vigor el 1 enero de $1958^{4}$.

$\mathrm{Al}$ entrar en vigor la CECA en 1952 y en el momento de la firma de los Tratados de Roma de las CEE en 1957, no existía, como expresé en el resumen inicial, una preocupación concreta por el medio

4 Igualmente, otras organizaciones especializadas de cooperación estaban convencidas de compartir un destino común, entre ellas: la Comunidad Europea de Defensa (CED), cuyo Tratado fue firmado el 27 de mayo de 1952; la Organización Europea de Cooperación Económica (OECE) constituida con el objetivo de reconstruir Europa con la ayuda norteamericana, que más tarde se convertiría en la Organización para la Cooperación y el Desarrollo Económicos (OCDE). Sobre esta organización, consúltese su dirección on line: http://www.oecd.org; la organización de defensa Unión Europea Occidental (UEO) integrada por diez países europeos: España, Bélgica, Francia, Alemania, Grecia, Italia, Luxemburgo, Holanda, Portugal y el Reino Unido; anunció su disolución tras la entrada en vigor del Tratado de Lisboa. Véase: http:// www.defensa.gob.es/politica/seguridad-defensa/contexto/europea-atlantica/UEO/; y, desde luego, el Consejo de Europa, organización de cooperación política fundada en 1949 y de distinto carácter de las CEE, pertenecen a ella todos los países europeos, y cuya sede está en Estrasburgo. El Consejo de Europa es garantía y baluarte, junto con su Tribunal Europeo de Derechos Humanos (TEDH), de la protección de los derechos humanos y de las libertades fundamentales de todos los europeos. Los 10 miembros fundadores fueron: Bélgica, Dinamarca, Francia, Irlanda, Italia, Luxemburgo, Países Bajos, Noruega, Suecia y Reino Unido. Los otros 37 Estados miembros, por orden de incorporación a los fundadores: Grecia, Turquía, Islandia, Alemania, Austria, Chipre. Suiza, Malta, Portugal, España, Liechtenstein, San Marino, Finlandia, Hungría, Polonia, Bulgaria, Estonia, Lituania, Eslovenia, República Checa, Eslovaquia, Rumania, Andorra, Letonia, Albania, Moldavia, Macedonia, Ucrania, Rusia, Croacia, Georgia, Armenia, Azerbaiyán, Bosnia- Herzegonvina, Serbia, Mónaco, Montenegro. Además tienen el estatus de Estados observadores: La Santa Sede, como así mismo, cinco Estados no europeos: EE.UU., Canadá, Japón, Israel y México. 
ambiente, y por tanto, no existía una política ambiental común ${ }^{5}$, como si era el caso, por ejemplo, de la política agrícola (artículos 3-4 y 38.4. ${ }^{\circ}$ del TCEE) o la política comunitaria de transportes (arts. 3.e) y 74 del TCEE). No obstante, los tratados creadores de la CECA y de la CEEA (1957) sí introdujeron ciertas referencias a cuestiones relacionadas con la protección del medio ambiente. El TCECA, hacía mención a ello en relación con la investigación de ciertos aspectos de la contaminación causada por las industrias del carbón y del acero. En el TCEEA, en relación con la seguridad en el trabajo y la protección sanitaria de la población en general, y algunos colectivos de trabajadores expuestos a las radiaciones nucleares, como lo demuestran los artículos 2.b), 30, 31, 35, 36 y 37 del TCEEA ${ }^{6}$ :

5 Consúltese Nascimbene, B., Ambiente (Tutela dell') (Diritto Comunitario) in Novissimo Digesto Italiano, Appendice. Torino. Editorial: Unione Tipografico-Editrice Torinese, 1980. Véanse las págs. 274 y ss. sobre los principios generales comunitarios del medio ambiente y la no existencia de una política común.

6 Consúltese en la dirección de legislación europea: http://eur-lex.europa.eu/es/ treaties/index.htm

También en: https://www.boe.es/legislacion/enlaces/documentos/ue/Tratados(0476-0576).pdf

Tratado Constitutivo de la Comunidad Europea de la Energía Atómica (TCEEA):

\section{Artículo 2}

Para el cumplimiento de su misión, la Comunidad deberá, en las condiciones previstas en el presente Tratado:

a) $1 \ldots /$

b) establecer normas de seguridad uniformes para la protección sanitaria de la población y de los trabajadores y velar por su aplicación;

\section{CAPÍTULO 3: Protección sanitaria}

\section{Artículo 30}

Se establecerán en la Comunidad normas básicas para la protección sanitaria de la población y los trabajadores contra los peligros que resulten de las radiaciones ionizantes.

Se entenderá por normas básicas:

a) las dosis máximas admisibles con un suficiente margen de seguridad;

b) las exposiciones y contaminaciones máximas admisibles;

c) los principios fundamentales de la vigilancia médica de los trabajadores.

\section{Artículo 31}

Las normas básicas serán elaboradas por la Comisión, previo dictamen de un grupo de personalidades designadas por el Comité Científico y Técnico entre los expertos científicos de los Estados miembros, especialmente entre los expertos en materia de salud pública. /.../

Todo Estado miembro, en cuyos territorios hayan de realizarse experimentos particularmente peligrosos, deberá adoptar disposiciones suplementarias para la protección sanitaria, después de haber recibido el dictamen de la Comisión sobre ellas. Se requerirá el dictamen favorable de la Comisión cuando los efectos de es- 
Es decir, se atendió a sectores laborales y sociales, abriendo paso a una incipiente política de salud pública relacionada con el medio ambiente?

Por otra parte, en el artículo 2 del TCEE ya aparecía como objetivo general de la $\mathrm{CE}$ «la mejora constante de las condiciones de vida y de trabajo en los EEMM», preocupación que tiene que ver profundamente con el entorno medioambiental. La Comunidad Europea fue evolucionando con prontitud, comenzando a elaborar su primera legislación medioambiental ${ }^{8}$ como resultado, sobre todo, de un proceso de concienciación social. El lema que eligió la CE en los años 70 fue «el medio ambiente no conoce fronteras».

tos experimentos pudieren dejarse sentir en los territorios de los restantes Estados miembros. /.../

\section{Artículo 35}

Cada Estado miembro creará las instalaciones necesarias a fin de controlar de modo permanente el índice de radiactividad de la atmósfera, de las aguas y del suelo, así como la observancia de las normas básicas. La Comisión tendrá derecho de acceso a estas instalaciones de control; podrá verificar su funcionamiento y eficacia.

\section{Artículo 36}

La información relativa a los controles mencionados en el artículo 35 será comunicada regularmente por las autoridades competentes a la Comisión, a fin de tenerla al corriente del índice de radiactividad que pudiere afectar a la población.

\section{Artículo 37}

Cada Estado miembro deberá suministrar a la Comisión los datos generales sobre todo proyecto de evacuación, cualquiera que sea su forma, de los residuos radiactivos, que permitan determinar si la ejecución de dicho proyecto puede dar lugar a una contaminación radiactiva de las aguas, del suelo o del espacio aéreo de otro Estado miembro. /.../

7 Precisamente, estas normas del capítulo III del TCEEA o EURATOM, referentes a la protección de las personas, dieron lugar a unas Directivas del Consejo de 2 de febrero de 1959 que establecían las normas básicas de seguridad relativas a la protección sanitaria de la población y los trabajadores contra los peligros que resultan de las radiaciones ionizantes.

Igualmente, tomando como referencia estas directivas en 1990 apareció la Directiva 90/641/Euratom del Consejo, concretamente de 4 de diciembre, relativa a la protección operacional de los trabajadores exteriores con riesgo de exposición a radiaciones ionizantes por intervención en zona controlada. Se puede consultar en Internet: http://eur-lex.europa.eu/LexUriServ/LexUriServ. do?uri=CELEX:31990L0641:ES:HTML

"En 1991, los ministros de Sanidad adoptaron Resoluciones sobre las opciones fundamentales de la política sanitaria y sobre la salud y el medio ambiente.» Véase sobre este particular el documento del Dr. J. Manuel SOBRINO HEREDIA «La Política de Salud Pública en la Unión Europea» : http://ruc.udc.es/dspace/bitstream/2183/1989/1/ AD-2-31.pdf

8 "La Unión Europea y el medio ambiente». Revista de la colección "Europa en movimiento». Luxemburgo. Ed. Oficina de Publicaciones Oficiales de las CEE., 1997; véase la pág. 7. 
La primera institución comunitaria en reaccionar a ese proceso de sensibilización fue el Parlamento Europeo'. En 1970, Franco Maria Malfatti, entonces Presidente de la Comisión Europea, "afirmó el propósito de recurrir al artículo 235 del Tratado Comunitario como soporte legal para establecer las regulaciones comunitarias directas en la materia medioambiental» ${ }^{10}$. Es por ello, que cuando las CEE comienzan a legislar sobre esta materia, atienden, sobre todo, «a la importancia de reducir la contaminación en el origen de la actividad o instalación presuntamente contaminante». La primera Directiva de medio ambiente se emitió en 1967 «sobre clasificación, embalaje y etiquetado de sustancias peligrosas» (67/548/CEE) y en 1970 se firmó la Directiva Marco sobre contaminación atmosférica producida por motores de explosión de los vehículos a motor (70/220/CEE).

Pero el verdadero impulso en el reconocimiento medioambiental viene de la mano del Informe dirigido al Club de Roma titulado Los límites del crecimiento, que constituyó la primera llamada de atención de las repercusiones nocivas de las acciones humanas sobre el Medio $^{11}$. Este Informe influyó decisivamente en la "Conferencia de las Naciones Unidas sobre el Medio Humano» que se celebró a continuación ese mismo año, hito del Derecho Internacional Público de Medio Ambiente y creadora de la «Declaración de Estocolmo sobre el Ambiente Humano» (1972), en la que se dispone que "los Estados deben responsabilizarse de que las actividades que se realicen dentro de sus fronteras, jurisdicción y control, no causen daño a las personas, al entorno natural ni al medio ambiente de otros Estados».

9 A raíz del envenenamiento del Rhin en 1969, véase el artículo de la Vanguardia en: html

http://hemeroteca.lavanguardia.com/preview/1969/06/27/pagina-20/33593720/pdf.

El Parlamento Europeo ya desde 1970 requiere a la Comisión la adopción de medidas pertinentes para el desarrollo y la coordinación de actuaciones de los Estados ribereños para la protección del Rhin.

10 Vercher Noguera, A., artículo: «La incipiente regulación de los delitos contra el medioambiente en el derecho comunitario europeo», pág. 30. Revista $n .^{\circ} 67$ Estudios de Derecho Judicial: "El derecho europeo medioambiental: estado actual de la transposición del derecho comunitario al ordenamiento jurídico». Ed.. Consejo del Poder Judicial y la Junta de Andalucía, 2004.

11 «El informe europeo fue dirigido por Meadows al frente de un equipo perteneciente al Instituto Tecnológico de Massachusetts. Se reconoce por primera que los recursos naturales no son ilimitados y que es la economía la que se debe de manejar de manera más cuidadosa.»Consúltese el documento de ESCHENHAGEN, M. ${ }^{a}$ Luisa: «Las cumbres ambientales internacionales y la educación ambiental». Estudio publicado en la Revista Oasis. Centro de Investigaciones y Proyectos Especiales. Universidad Externado de Colombia, 2006/7; pág. 6 del documento: http://www.pensamientoambiental.de/images/cumbres.pdf 
Ese mismo año, se tomó una decisión política en la Conferencia de Jefes de Estado y de Gobierno europeos celebrada en octubre, en la que se confirmó la necesidad de establecer una política medioambiental. En este Consejo Europeo participaban los nueve EEMM de aquel momento, proclamando «la necesidad de mejorar la calidad de vida de los europeos»" ${ }^{12}$, "considerando al mismo tiempo, que una política ambiental comunitaria habría de estar muy relacionada con las otras políticas comunitarias ${ }^{13}$, la industrial y energética, la regional, la social, ...,» ello dio lugar a la elaboración del «Primer Programa de las Comunidades Europeas de Acción Medioambiental» para el periodo 1973-76.

\section{MODOS DE ATRIBUCIÓN DE COMPETENCIAS A LAS CEE (ACTUALMENTE UE) POR PARTE DE LOS ESTADOS MIEMBROS. LA COMPETENCIA AMBIENTAL}

Las competencias que tiene atribuidas la UE tienen su origen preciso en una transferencia de atribuciones de los Estados miembros (EEMM) a la Unión, es decir, que «los EEMM han limitado voluntariamente, en ámbitos concretos, sus derechos soberanos».

Por tanto, existen algunos ámbitos donde los EEMM tienen sus competencias cedidas a la Unión, completamente, o simplemente en parte, es decir, en este segundo caso los Estados tienen algunas políticas «compartidas» (reguladas en parte por el ordenamiento de la UE), éste es el caso de la política de medio ambiente. Es por ello necesario dilucidar los casos en que pueda producirse alguna «colisión de competencias», saber qué derecho es el aplicable y hasta dónde. Dado que, en principio, "el Derecho comunitario, como ordenamiento jurídico integrado en el sistema jurídico de los EEMM incide directamente en el derecho soberano de estos Estados» ${ }^{14}$.

12 Coord. H. SAND, P.; The effectiveness of international environmental agreements A Survey of Existing Legal Instrument»; Inglaterra. Ed. Grotius Publications England Ltd., 1992; págs. 45-47.

13 Moussis, N., Les politiques de la Communauté économique européenne; Paris. Editorial Dalloz. 1982; pág. 249.

${ }_{14}$ En la práctica, la Corte Europea introdujo el principio del efecto directo de la ley comunitaria en el ordenamiento interno de los EEMM en 1963 con el caso de Van Gend y Loos, el cual capacita a los ciudadanos europeos a confiar directamente en la normativa de la Unión Europea ante sus ordenamientos nacionales. La compañía Van Gend \& Loos había importado mercancías desde Alemania para llevarlas a Los Países Bajos y ser vio obligada a pagar unos derechos de aduana que consideró incompatibles con la normativa del TCEE que prohibía incrementos en las tasas de aduana cuando los bienes o mercancías se comercian entre los EEMM. La 
En 1964, el Tribunal de Justicia de las Comunidades Europeas (TJCE) emitió su famosa sentencia conocida como: «Costa contra E.N.E.L», donde "el Tribunal de la CE aporta una interpretación de la noción de soberanía muy alejada de su configuración tradicional en el marco de la Teoría del Estado», y que asentaba, al mismo tiempo, las bases de «la doctrina de la primacía del Derecho comunitario sobre los ordenamientos jurídicos de los EEMM». He aquí una de las frases de la sentencia: «A las normas comunitarias no es oponible ningún acto unilateral posterior de un Estado miembro» ${ }^{15}$. La jurisprudencia del Tribunal de Justicia de la Unión Europea (TJUE) es inamovible a la hora de afirmar la primacía de todo el derecho comunitario, incluidos los acuerdos con terceros y el derecho derivado, frente al derecho de los Estados miembros, incluidas sus normas constitucionales ${ }^{16}$.

acción puso en evidencia la cuestión de conflicto entre la legislación nacional y las provisiones del TCEE. La Corte de la Comunidad Europea decidió la cuestión con referencia a un tribunal neerlandés afirmando la doctrina del efecto directo, y así confiriendo a la compañía de transporte una garantía directa de sus derechos bajo las leyes de la Comunidad.

"In practice the European Court introduced the principle of the direct effect of Community law in the Member States in 1963, with the case of Van Gend \& Loos, which enables European citizens to rely directly on rules of European Union law before their national courts. The transport company Van Gend \& Loos had imported goods from Germany to the Netherlands and had to pay customs duties which it considered to be incompatible with the rule in the EEC Treaty prohibiting increases in customs duties in trade between Member States. The action raised the question of the conflict between national legislation and the provisions of the EEC Treaty. The Court decided the question referred by a Netherlands court by stating the doctrine of direct effect, thus conferring on the transport company a direct guarantee of its rights under Community law» . http:// www.duhaime.org/LegalDictionary/C/CommunityLaw.aspx

Véase, si se desea, la administración del procedimiento del caso Van Gend \& Loos en la dirección de Internet: http://www.bailii.org/eu/cases/EUECJ/1963/R2662.html

15 Véase la Sentencia del Tribunal de Luxemburgo de 15 de julio de 1964 sobre el asunto 6/64 : «M. Flamio Costa contra ENEL». Se puede acceder a la administración del procedimiento del caso en la dirección de Internet: http://www. bailii.org/eu/cases/EUECJ/1964/C-664.html.

Consúltense igualmente, el interesante y pormenorizado estudio, con comentarios a esta sentencia, en el libro del Dr. y Catedrático PUENTE EGIDO, J., Casos prácticos de Derecho Internacional Público, Madrid. Ed. EDISOFER, 3. a edición revisada, diciembre 2001.

16 Remiro Brotóns, A., Derecho Internacional; Ed. Tirant lo Blanch, 1. a edición, Valencia 2007, dice en la pág. 666: "No obstante, algunos pronunciamientos de los tribunales de los EEMM, como son los de la Corte Constitucional italiana (Frontini, 1973, Granital, 1984, Fragd, 1989) y del Tribunal Federal alemán (Solange I, 1974, Solange II, 1986, Constitucionalidad del TUE, 1993) han puesto en entredicho la primacía del Derecho Comunitario respecto a las Constituciones estatales, y con ello, han cuestionado el control de validez de los actos de Derecho derivado.» 
Por ello, en lo que se refiere a política medioambiental, la UE se ha estado presentando ante la Comunidad Internacional como un sistema regional integrado, generador de derecho obligatorio, al tiempo que asegura la debida eficiencia y efectividad en lo que al procedimiento de este derecho comunitario se refiere ${ }^{17}$.

17 Cuando la Comisión Europea recibe una denuncia por contaminación ambiental, ya provenga ésta directamente de un Estado miembro, o de un ciudadano de un EEMM, la misión de la Comisión es «iniciar su acción de custodia», (profundizando en la investigación del asunto para confirmar con certeza suficiente si hay o no incumplimiento). En la práctica, la Comisión actúa como un «Ombudsman» en defensa del medio ambiente europeo, planteando un recurso ante el TJUE e iniciándose un procedimiento con suficientes garantías para la parte que ha demandado dicha custodia.

Este eficaz procedimiento es único en el mundo, dado que los procedimientos medioambientales no suelen operar con la suficiente protección en otras regiones del globo. Así, es frecuente, que ante la denuncia de un ilícito internacional de medio ambiente, no se suelen aplicar los principios del derecho procesal, ni principios básicos de una investigación equilibrada para las partes que establezca una verdadera seguridad bilateral en los procedimientos, brindándole a las partes la posibilidad de ser oídas en cada uno de los momentos del proceso. Por el contrario, la parte denunciante (si es una persona física y/o jurídica, y no un Estado u organización internacional) suele no tener derecho a recursos de ninguna especie (y redundo, éste no es el caso de la UE). Razón por la cual, si una petición no es acogida a tramitación, no existe para la parte que la presenta posibilidad alguna de ser oída. Dentro del procedimiento, para la parte demandante, tampoco existe posibilidad de discusión respecto a la interpretación que los órganos oficiales hagan de su petición de protección ambiental. De hecho, la «parcialidad de los órganos» (en su gestión e interpretación) del acuerdo internacional o regional medioambiental del que se trate (o clausula medioambiental a aplicar dentro de otro tipo de acuerdo) es un problema legal de forma, que no es menor, pues esta falta de ecuanimidad repercute en la investigación de cuestiones de fondo en el procedimiento de los asuntos ambientales. De esta manera, la denuncia no suele conducir a una resolución efectiva del asunto; el resultado final al que acceden los peticionarios de protección, se queda en una mera «conformación de un expediente de hechos que, a solicitud de cualquiera de las partes, podría hacerse público».

La segunda parte del ineficiente procedimiento descrito, es que si un expediente de hechos constata la omisión de la aplicación efectiva de la legislación ambiental por parte del supuesto infractor, no implica forzosamente que la parte denunciada tenga que realizar acción alguna para terminar con ese incumplimiento, porque las conclusiones del expediente de los hechos no suelen tener un carácter vinculante; no produciéndose un cumplimiento eficaz de la legislación medioambiental del acuerdo o cláusula de que se trate. Es más, los órganos que tienen atribuida «la competencia de revisar e investigar» las peticiones de denuncia, "carecen de facultades jurisdiccionales propiamente dichas».

En línea con lo expuesto, tomemos el ejemplo del Acuerdo de Cooperación ambiental entre EE.UU., Canadá y México; entre 1977 y el año 2000 fueron presentadas 28 peticiones, de las cuales sólo 2 de ellas dieron lugar a la iniciación de un expediente acerca de los hechos denunciados, y ninguna de ellas llegó a concluir celebrándose todo el procedimiento.

Consúltese al respecto la página 7 del revelador documento titulado «Acuerdos ambientales anexos a tratados de libre comercio, un fraude para nuestros 
La política medioambiental comunitaria es uno de los sectores más exitosos en comparación con otros países u otras organizaciones internacionales (sean éstas de ámbito regional o internacional), además, poseemos el cuerpo normativo en esta materia más extenso del mundo ${ }^{18}$. De hecho, la UE siempre ha sido precursora en el ámbito medioambiental, por ejemplo, con el ya citado Informe del Club de Roma titulado Los límites del crecimiento, que influyó decisivamente en la ya también mencionada Declaración Internacional de Estocolmo de 1972, considerada como primer derecho fundacional medioambiental ${ }^{19}$. Esta Declaración exhibe 106 Recomendaciones y 24 Principios a seguir para la conservación y protección del Medio Ambiente. Según el Dr. D. Manuel Díez de Velasco, «la Declaración allí aprobada describió del modo más amplio posible el entorno ecológico humano y enunció el principio programático medioambiental» ${ }^{20}$.

Efectivamente, la UE, desde que lanzara su «Primer Programa de Acción de las Comunidades Europeas sobre Medio Ambiente (19731976)», no ha cesado de intentar progresar en sus acciones ambientales. Así, en 1977 anunció su «Segundo Programa (1977-1981)», y en 1982 el «Tercero (1982-1986)». El año 1987 fue declarado «Año Europeo del Medio Ambiente» y se adoptó el «Cuarto Programa de Acción para el periodo 1987-1992». Otros Programas de Acción Medioambiental fueron aprobados para los tramos anuales siguientes. Ade-

pueblos» redactado por CAVIERES SEPÚLVEDA, Yénive; Abogada y Encargada del Área Jurídica del "Observatorio Latinoamericano de Conflictos Ambientales» (OLCA). Denuncia esta abogada: "Que en términos normativos, este sistema es también ineficaz e ineficiente ya que no logra el acatamiento de sus normas por sus destinatarios, y con esto, el cumplimiento de los fines objetivos ambientales que el Acuerdo de Cooperación Ambiental entre Chile y Canadá se plantea. Tampoco es idóneo para satisfacer la necesidad jurídica que se tuvo en cuenta en la formación de este acuerdo, esto es, la necesidad de resolución de los conflictos ambientales.»

${ }_{18}$ La extensa legislación medioambiental de la UE puede ser consultada en la siguiente dirección: http://europa.eu/pol/env/index_en.htm

19 Creando el Programa de las Naciones Unidas para el Medio Ambiente (PNUMA), principal programa de las NNUU a cargo de los asuntos del medio ambiente; con la asistencia de 113 países. Debatiéndose por primera vez la problemática medioambiental y su importancia para el ser humano y los demás seres vivos.

20 "(...) Los dos aspectos del medio humano, el natural y el artificial, son esenciales para el bienestar del hombre y para el goce de los derechos humanos fundamentales, incluso el derecho a la vida misma».

"La protección y mejoramiento del medio humano es una cuestión fundamental que afecta al bienestar de los pueblos y al desarrollo económico del mundo entero. (...)». Párrafo extraído de la pág. 764. de la obra de DIEZ DE VELASCO, M., Instituciones de Derecho Internacional Público; Madrid, Editorial Tecnos (Grupo Anaya, S.A.), decimosexta edición, 2007.

Texto de la Declaración de Estocolmo: http://www.ambiente.gov.ar/infotecaea/ descargas/estocolmo01.pdf 
más, a estos programas quinquenales hay que añadir la elaboración constante de Directivas obligatorias para los EEMM ${ }^{21}$.

La Comisión Europea siempre ha sido puntera en promover la mejora de la legislación. Por esta razón, la Comisión inició el Programa "Legislar mejor» con dos iniciativas clave: el «Libro Blanco de 2001 de la Comisión sobre la gobernanza europea» y la "Estrategia de Lisboa». La iniciativa procedía del Consejo de Lisboa de 2000, cuando los líderes de la Unión habían pedido a la Comisión que instaurara, a más tardar en 2001, una estrategia para una actuación más coordinada orientada a simplificar el marco regulador, tanto a escala nacional como comunitaria. Por tal motivo, en 2002, la Comisión publicó el Plan de acción «Simplificar y mejorar el marco regulador ${ }^{22}$, ello repercutió directamente en la política y legislación medioambiental de la Unión. Además, en la línea de Kyoto ${ }^{23}$, la UE

21 Así, la Directiva 85/337/CEE del 27 de junio de 1985, relativa a la evaluación de las repercusiones de proyectos públicos y privados sobre el medio ambiente. En abril del 1993 la Comisión emite un Informe sobre la directiva del 85 y el 3 de marzo de 1997 se modifica la Directiva 85/337/CEE con otra del Consejo: Directiva 97/11/CE.

Se puede consultar la abundante legislación de la UE en medio ambiente en su dirección oficial a través de internet. En defensa de la contaminación del aire en: http://ec.europa.eu/environment/air/legis.htm destacando la Directiva 2008/50/CE sobre la calidad del aire ambiente y una atmósfera más limpia en Europa, que tiene en cuenta la fusión de la mayor parte de la legislación existente en una única directiva (a excepción de la Cuarta Directiva de desarrollo ) para conseguir una mayor eficacia en la aplicación de la normativa. Igualmente, se puede consultar la legislación sobre el agua en: http://water.europa.eu/ ; en este ámbito destaca la Directiva. 2000/60/CE, por la que se establece un Marco Comunitario de Actuación en el Ámbito de la Política de Aguas (conocida como DMA), se publicó en el Diario Oficial (DO L 327) el 22 de diciembre de 2000 y entró en vigor ese mismo día.

Es de recordar, por su importancia, la Directiva 2008/1/CE del Parlamento Europeo y del Consejo, de 15 de enero de 2008, relativa a la prevención y al control integrados de la contaminación: conocida como la Directiva IPPC y que codifica la Directiva 96/61/CE, a la que sustituye.

22 Véase COM (2002) 278. Acompañaban este Plan otras dos Comunicaciones: sobre la mejora de la consulta pública en las propuestas legislativas de la Comisión (COM (2002) 277); y sobre la introducción de un sistema para evaluar las posibles repercusiones económicas, sociales y medioambientales de las propuestas de la Comisión (COM (2002) 276). El debate final sobre la elaboración del Sexto Programa de Acción en Materia de Medio Ambiente se vio influido en gran medida por el «proceso de Legislar mejor» y en particular por las siete estrategias temáticas basadas en evaluaciones de impacto.

${ }_{23}$ El Protocolo de Kyoto (fruto de la Convención Marco de NNUU de 1992, conocida como Cumbre de la Tierra celebrada en Río de Janeiro) había sido aprobado el 11 de diciembre de 1997 y que entró finalmente en vigor el 16 de febrero de 2005, después de la ratificación de Rusia, pues se necesitaban al menos, la ratificación de 55 Partes firmantes de la Convención. Nuestra CE había depositado el instrumento de ratificación del Protocolo en mayo del año 2002. No pasemos por alto la no ratificación de los EEUU. 
aprobó un Programa sobre el cambio climático con el fin de alcanzar los objetivos fijados en el cuadro del Protocolo ${ }^{24}$.

\section{En febrero de 2007, los Ministros de Medio Ambiente de la UE} en una reunión celebrada en Bruselas, acordaron dar una respuesta especialmente comprometida, ya dada a entrever en 2006 para reducir para el año 2020 las emisiones de $\mathrm{CO}_{2}$ a un nivel inferior en un $20 \%$ al de los emitidos en 1990. Es más, la Unión deseaba un compromiso de reducción superior, hasta del 30\%, siempre que otras potencias industrializadas se sumaran ${ }^{25}$. Al mes siguiente, marzo de 2007, la lucha contra el cambio climático fue protagonista de nuevo

24 La Comisión Europea, ya antes de la ratificación europea de Kyoto en 2002, había puesto en marcha en el año 2000 una estructura destinada a identificar y preparar la ejecución de las medidas de lucha contra el cambio climático a través del «Programa Europeo sobre el Cambio Climático» (PECC) cuyo objetivo consistía en permitir a todas las partes interesadas participar en los trabajos preparatorios de las políticas y medidas destinadas a reducir las emisiones de gas de efecto invernadero. Este Plan puesto en marcha en junio del 2000, no sería el único, fue actualizado con un Segundo Programa Europeo sobre el Cambio Climático (PECC II) que se puso en funcionamiento en octubre de 2005. Ello fue impulsado por la Comunicación de la Comisión, de 9 de febrero de 2005, "Ganar la batalla contra el cambio climático mundial»: COM (2005) 35 final que aparece en el DOUE C 125 de 21 de mayo de 2005.

25 La UE fijó límites nacionales de «emisiones de contaminación atmosférica» para cuatro tipos de contaminantes, que entrarían en vigor en 2010. Los contaminantes son: dióxido de azufre $\left(\mathrm{SO}_{2}\right)$, óxidos de nitrógeno (NOx), compuestos orgánicos volátiles $(\mathrm{COV})$ y amoniaco $\left(\mathrm{NH}_{3}\right)$. Las autoridades de los EEMM deberían confeccionar inventarios nacionales de estos contaminantes y tomar medidas para minimizar sus emisiones, pudiendo imponerse obligaciones a escala nacional para las empresas que los emitan.

Asimismo, la Unión fijó «una serie de límites para las concentraciones de gases invernadero en el aire»: de dióxido de azufre, dióxido de nitrógeno y óxidos de nitrógeno, partículas y plomo. Las autoridades nacionales habrían de llevar un control de los niveles de estas sustancias en la atmósfera y tomar las medidas oportunas para garantizar que se mantengan por debajo de los límites. De hecho, desde 2005 ya existía en la UE, un Régimen para el Comercio de emisiones (ETS) que se ha ido implantando en más de 11.500 instalaciones de consumo intensivo de energía de toda la UE. Las instalaciones a las que afecta el Régimen ETS suponían en esos momentos aproximadamente la mitad de las emisiones de $\mathrm{CO}_{2}$ de la UE: plantas de combustión, refinerías de petróleo, hornos de coque, acerías y fábricas de cemento, vidrio, cal, ladrillos, productos cerámicos, pasta y papel. Los gobiernos nacionales asignan, a las plantas industriales afectadas por el régimen, cuotas para emitir determinadas cantidades de $\mathrm{CO}_{2}$ con arreglo a un «Plan Nacional de Asignación (PNA)». Las empresas pueden comprar o vender cuotas de emisión dentro de un sistema de mercado. De este modo, existe un incentivo económico a la reducción de emisiones y se garantiza el cumplimiento de los objetivos con un coste mínimo. Las cuotas que se compran y venden dentro del régimen de la ETS de la Unión quedan almacenadas en registros electrónicos nacionales, que después se consolidan en un registro general de transacciones independiente comunitario. Este sistema de registros lleva un control de la titularidad de las cuotas del mismo modo que un sistema bancario lleva un control de la titularidad del dinero. 
en la primera cumbre de la Unión Europea presidida por la canciller alemana Angela Merkel. La ardua discusión sobre las energías renovables era toda una prueba de fuego, porque ligada a la reducción del $\mathrm{CO}_{2}$ se acompañaba otra iniciativa mucho más controvertida en el seno de la UE, la de cubrir hasta el año 2020 el 20\% de las necesidades energéticas con energías renovables, como la solar, la hidráulica y la eólica, que hasta ese momento representaban sólo el 6,5\% del total ${ }^{26}$.

En junio de 2008 la UE emite un documento técnico sobre el "Cambio climático y el agua» ${ }^{27}$, y sin dejar tregua, en abril de 2009, la Comisión Europea exhibe el «Libro Blanco de adaptación al cambio climático (CC) ${ }^{28}$, que presenta el marco para las medidas de adaptación y las políticas para reducir la vulnerabilidad de la UE a los impactos del CC. Así, en relación a las medidas efectivas a tomar, aparece en ese mismo año el «Dictamen del Comité de Regiones» ${ }^{29}$ que señala: "Dado que las medidas de adaptación que aparecen en el Libro, son en muchos casos esfuerzos realizados básicamente a nivel local, resulta esencial que los entes locales y regionales cuenten con el apoyo de la UE». (...)

En diciembre de 2009, aparece un «Documento de orientación sobre la adaptación al CC en la gestión del agua» para salvaguardar

26 Destaca en este sentido, la Comunicación de la Comisión al Parlamento Europeo, al Consejo, al Comité Económico y Social y al Comité de las Regiones de 23 de enero de 2008, "Dos veces 20 para el 2020. El cambio climático, una oportunidad para Europa». Más tarde, el Tratado de Lisboa regula de manera independiente la Política de Energía en el Título XXI, art. 194, después del título dedicado al medio ambiente, denotando así la nueva importancia que se atribuye a este compromiso energético. Asimismo, como el medio ambiente, no sólo está altamente relacionado con la energía sino también con los transportes, en 2001 se formuló una Decisión, la Decisión 2001/546/CE de la Comisión, de 11 de julio de 2001, por la que se crea un Comité consultivo llamado "Foro europeo de la energía y los transportes», véase en el DOUE L 195 de 19 de julio de 2001; este Foro tenía por objeto el crear un foro consultivo de personalidades cualificadas de los sectores de la energía y los transportes, a fin de emitir dictámenes sobre cualquier iniciativa de la Comisión en materia de política de energía y transportes. Asimismo, se pensaba que hiciera las veces de observatorio, en relación con la competitividad y la adaptación de las estructuras de esos sectores, teniendo muy en cuenta las preocupaciones medioambientales, sociales y de seguridad.

27 Sobre el documento, consúltese: http://ec.europa.eu/environment/water/adaptation/index_en.htm

28 Libro Blanco «Adaptación al cambio climático: Hacia un marco europeo de actuación». Publicado en Bruselas en abril de 2009: COM (2009) 147 final.

Consúltese el Libro en: http://eur-lex.europa.eu/LexUriServ/LexUriServ. do?uri=COM:2009:0147:FIN:Es:PDF

${ }_{29}$ Véase: http://eur-lex.europa.eu/LexUriServ/LexUriServ.do?uri=OJ:C:2010:079 :0013:0018:ES:PDF 
los planes hidrológicos de cuenca. Y en 2010, puesto que el cambio climático afecta también a los bosques y sus ecosistemas circundantes, aparece el "Libro Verde sobre protección de los bosques e información forestal en la UE: Preparación de los bosques al cambio climático» ${ }^{30}$. Este Libro prevé «una explotación y una corta sostenibles de la madera», así como, inversiones en operaciones forestales para aumentar la estabilidad y resistencia de los bosques frente a los impactos del $\mathrm{CC}^{31}$.

Por último, y aunque no puedo ser exhaustiva en este breve artículo, sí debo, no obstante, acentuar en esta escueta pero importante mención de legislación ambiental comunitaria, que la biodiversidad constituye un elemento clave para la adaptación al CC y la mitigación de sus consecuencias, destacando al respecto, en mayo de 2011, la Comunicación de la Comisión al Parlamento Europeo, al Consejo, al Comité Económico y Social Europeo, y al Comité de las Regiones, titulada "Estrategia de la UE sobre la biodiversidad hasta 2020: nuestro seguro de vida y capital natural» ${ }^{32}$.

En base a lo recién expresado en los párrafos anteriores, aunque solemos referirnos a una Politica comunitaria de Medio Ambiente "compartida», podemos comprobar, no obstante, que la UE interviene muy activamente para tratar de conseguir una serie de fines ambientales bien delimitados en todo el territorio de los EEMM: "preservar, proteger y mejorar la calidad del medio ambiente; proteger la salud de las personas y promover una utilización racional y prudente de los recursos naturales, fomentando además medidas a escala internacional para hacer frente a los problemas regionales o mundiales relacionados con el medio ambiente». Así, aún sin encontrarnos ante una política común, no deberíamos albergar dudas de la importancia que la Unión atribuye a este área, y su repercusión en la Comunidad internacional, es decir, en las Declaraciones y en la legislación general de Derecho Internacional Público que se adoptan en este ámbito.

Continuando con el cuadro de "reparto de competencias», cuestión sobre la que ya se debatía en los albores de la cooperación europea, cuando en el encuentro de La Haya de 1948 se hablaba de «divisibilidad» y de la posibilidad de «transferencia» de la soberanía

\footnotetext{
$30 \quad$ Véase la COM (2010) 66 final; publicada en Bruselas en marzo de 2010.

31 "La biodiversidad aumenta la resistencia y la capacidad de adaptación de los bosques. Los tipos de hábitats forestales designados por Natura 2000 ocupan más de 14 millones de hectáreas, lo que equivale a casi el $20 \%$ de todos los espacios terrestres de esa red.» (Párrafo extraído de la pág. 9 del Libro Verde).

32 Véase la Comunicación publicada en Bruselas el 3 de mayo de 2011: $\operatorname{COM}(2011) 244$ final
} 
de los EEMM, o al menos, de algunas parcelas de soberanía hacia la CE. Tal noción fue sustituida más tarde por la de "atribución» a través de la jurisprudencia del Tribunal de Justicia de las CEE (TJCE), hoy TJUE. Esta atribución ha sido mayormente de tipo funcional y limitada a los objetivos de la Unión ${ }^{33}$.

\section{El reparto de competencias entre la Unión Europea y sus EEMM permitiría distinguir tres categorías de competencias diferentes $^{34}$ :}

- Las competencias concurrentes o compartidas (el caso más frecuente), que en la actualidad aparecen mencionadas en el art. 4 del Tratado de Funcionamiento de la UE (TFUE) del Tratado de Lisboa (TL), apartado $1^{\circ}{ }^{\circ}$, que con expresión genérica señala: «que la Unión dispondrá de competencia compartida con los EEMM cuando los Tratados le atribuyan una competencia que no corresponda a los ámbitos mencionados en los artículos 3 y 6». ¿Cuáles son esos ámbitos?, pues los de las competencias exclusivas que se mencionan en el art. 3 y las competencias de acción en ámbitos de apoyo del art. 6.

El apartado $2 .^{\circ}$ de este art. $4 .^{\circ}$ menciona específicamente los ámbitos de las competencias compartidas: «el mercado interior; la política social (en los aspectos definidos en el Tratado);

33 Entre las posibles fuentes para profundizar más en este tema, recomiendo el artículo de escrito por Encarna Hernández «¿Cómo se articula el reparto de competencias entre la UE y sus EEMM?. Algunas nociones y un poco de historia» de la Revista electrónica "Más Europa», del n. ${ }^{\circ}$ de octubre de 2009.

http://encarnahernandez.wordpress.com/2009/10/25/\%c2\%bfcomo-se-articula-elreparto-de-competencias-entre-la-ue-y-sus-estados-miembros-algunas-nociones-yun-poco-de-historia/

34 Sobre las competencias, véase el libro de: VIDAL BELTRÁN, J. María, GARCÍA HERRERA, M. Ángel, y otros. El Estado autonómico. Integración, solidaridad, diversidad (vol. I), 1. a edición octubre 2005. Colección Estudios Goberna. Ed.: Instituto Nacional de Administración Pública (INAP) Editorial Colex. El capitulo donde se menciona a BogDANDY, A. V. y BAST, J sobre el «orden competencial vertical de la Unión Europea» en la página 278 y ss., es el capítulo escrito por MARTÍNEZ SIERRA, J. M., y nos recuerda que BogDANDY, en un seminario internacional titulado «La Encrucijada Constitucional de la UE» organizado por el Colegio Libre de Eméritos, celebrado en 2001 en la Real Academia de Ciencias Morales y Políticas en Madrid, habló de la especial problemática de las competencias comunitarias en el caso de los Estados descentralizados europeos, el caso de los Länders alemanes y de las Comunidades Autónomas españolas.

Consúltense también los artículos del Tratado de Lisboa, TFUE, Primera Parte, Título I «Categorías y Ámbitos de competencias de la Unión» (artículos 2, 3, 4, 5 y 6). On line:

http://eur-lex.europa.eu/LexUriServ/LexUriServ.do?uri=OJ:C:2010:083:FULL:ES :PDF

(C) UNED. Revista de Derecho UNED, núm. 12, 2013 
la cohesión económica, social y territorial; la agricultura y la pesca (con exclusión de los recursos biológicos marinos -que ahora es exclusiva-); el medio ambiente; la protección de los consumidores; los transportes; las redes transeuropeas; la energía; el espacio de libertad, seguridad y justicia; y los asuntos comunes de seguridad en materia de salud pública (en los aspectos definidos en el presente Tratado).»

Por otra parte, el art. 2, 2. ${ }^{\circ}$ del TFUE del TL expresa unas claras directrices de comportamiento al respecto de las competencias compartidas. Este artículo deja a los EEMM una competencia residual hasta donde la Unión no haya ejercido su competencia o deje de ejercerla. El artículo se expresa en estos términos: "Cuando los Tratados atribuyan a la Unión una competencia compartida con los EEMM en un ámbito determinado, la Unión y los EEMM podrán legislar y adoptar actos jurídicamente vinculantes en dicho ámbito. Los EEMM ejercerán su competencia en la medida en que la Unión no haya ejercido la suya. Los EEMM ejercerán de nuevo su competencia en la medida en que la Unión haya decidido dejar de ejercer la suya.»

- Las competencias comunitarias exclusivas son aquellas en que los EEMM han renunciado irrevocablemente a toda posibilidad de acción, dejando esas competencias en manos de la Unión, en definitiva, son las políticas comunes. En este sentido, el art. 3 del TFUE del TL dice así: ${ }^{35}$

1. «La Unión dispondrá de competencia exclusiva en los ámbitos siguientes:

a) la unión aduanera;

b) el establecimiento de las normas sobre competencia necesarias para el funcionamiento del mercado interior;

c) la política monetaria de los Estados miembros cuya moneda es el euro;

d) la conservación de los recursos biológicos marinos dentro de la política pesquera común;

e) la política comercial común.

35 Se puede consultar la versión consolidada del Tratado de Funcionamiento de la UE (TFUE) en el DOUE C115/47de 9 de mayo de 2008. Dirección de Internet: http://eur-lex.europa.eu/LexUriServ/LexUriServ.do?uri $=\mathrm{OJ}: \mathrm{C}: 2008: 115: 0047: 0199: \mathrm{es}: \mathrm{PDF}$ 
2. La Unión dispondrá también de competencia exclusiva para la celebración de un acuerdo internacional cuando dicha celebración esté prevista en un acto legislativo de la Unión, cuando sea necesaria para permitirle ejercer su competencia interna o en la medida en que pueda afectar a normas comunes o alterar el alcance de las mismas.»

- Las competencias o ámbitos de apoyo, sirven para llevar a cabo acciones con el fin de apoyar, coordinar y complementar o animar la acción de los EEMM en los ámbitos de finalidad europea. Están recogidas en el art. 6 del TFUE del TL:

«La Unión dispondrá de competencia para llevar a cabo acciones con el fin de apoyar, coordinar o complementar la acción de los Estados miembros. Los ámbitos de estas acciones serán, en su finalidad europea:

a) la protección y mejora de la salud humana;

b) la industria;

c) la cultura;

d) el turismo;

e) la educación, la formación profesional, la juventud y el deporte;

f) la protección civil;

g) la cooperación administrativa.»

Efectivamente, los Tratados recogen un método funcional de atribución de competencias, concediéndose "competencias específicas» en función de "objetivos a cumplir» y de "acciones a realizar» para tales fines ${ }^{36}$. Es decir, que al contrario que el Estado, que tiene una "finalidad integral» con fines y poderes generales, la Unión ostentaría una "finalidad unas veces, expresa y explícita, y en otras ocasiones funcional, e incluso de apoyo o cooperación», donde se habría de encuadrar la competencia o poder que se le otorga ${ }^{37}$.

\section{De acuerdo con el método de atribución, existen tres tipos de competencias ${ }^{38}$ :}

- Competencias explícitas: aquellas que están claramente indicadas en los correspondientes artículos de los Tratados.

36 ISAAC, G., Manual de derecho comunitario general, Barcelona. Editorial Ariel. (2. ${ }^{\text {a }}$ edición revisada), 1991; pág. 38

37 Ob. cit., Mangas Martín, A. y Liñán Nogueras, D. J., Instituciones...; pág. 115.

38 Consúltese: http://europa.eu/scadplus/glossary/community_powers_es.htm

(C) UNED. Revista de Derecho UNED, núm. 12, 2013 
- Competencias implícitas: aquellas que se derivan de la existencia de una competencia ya expresa o explícita a nivel interno. Por tanto, habida cuenta de que los Tratados otorgan a la Unión competencias explícitas en un ámbito concreto (por ejemplo, en transporte), la Unión debe tener competencias análogas para poder celebrar en ese mismo ámbito acuerdos con terceros países (principio del paralelismo entre las competencias internas y externas). Podemos encontrar la referencia al respecto en el art. 3.2 del TFUE del TL ${ }^{39}$.

- Competencias subsidiarias: cuando no existe competencia explícita o implícita para lograr algún objetivo del Tratado relacionado con el mercado único, el artículo 308 del antiguo $\mathrm{TCE}^{40}$ permitía al Consejo adoptar por unanimidad las medidas que considerara oportunas. Ahora, el TFUE en su art. 352.1 del TFUE del TL aporta una redacción mejorada: "Cuando se considere necesaria una acción de la Unión en el ámbito de las políticas definidas en los Tratados para alcanzar uno de los objetivos fijados por éstos, sin que se hayan previsto en ellos los poderes de actuación necesarios a tal efecto, el Consejo adoptará las disposiciones adecuadas por unanimidad, a propuesta de la Comisión y previa aprobación del Parlamento Europeo. $/ \ldots / »^{41}$.

En base a todo lo expresado anteriormente, la «competencia compartida en medio ambiente entre la Unión y sus EEMM ${ }^{42}$, no impide que exista un elevado nivel de coordinación entre la UE y sus Estados", facilitado además por la concreta normativa que se recogió en el Título XIX del TCE del Tratado de Niza de 2001, cuya

39 Según art. 3.2 del TFUE: «La Unión dispondrá también de competencia exclusiva para la celebración de un acuerdo internacional cuando dicha celebración esté prevista en un acto legislativo de la Unión, cuando sea necesaria para permitirle ejercer su competencia interna o en la medida en que pueda afectar a normas comunes o alterar el alcance de las mismas.»

40 El art. 308 del TCE antiguo disponía: "Cuando se considere necesaria una acción de la Unión resulte necesaria para lograr, en el funcionamiento del mercado común, uno de los objetivos de la Comunidad, sin que el presente Tratado haya previsto los poderes de acción necesarios al respecto, el Consejo, por unanimidad, a propuesta de la Comisión y previa consulta al Parlamento Europeo, adoptará las disposiciones pertinentes. /.../».

41 He subrayado esa última frase para no pasar por alto el reforzamiento al Parlamento Europeo, ahora no basta la previa consulta al Parlamento, sino su previa aprobación.

42 Ya el artículo 130R.4 del TCEE del Acta Única, había dejado claro el carácter no exclusivo de la competencia de la CE en medio ambiente, aunque incluyera la idea de coordinar las distintas instituciones comunitarias, nacionales y locales, para conseguir resultados adecuados en el respeto medioambiental. 
inclusión sirvió para superar «el escaso apoyo jurídico que hasta entonces había tenido la Comunidad Europea para sustentar su política medioambiental ${ }^{43}$. Más tarde ese Título XIX, sería reforzado por el fallido Tratado Constitucional, y después lo ha sido por el Tratado de Lisboa en vigor ${ }^{44}$.

\section{EL ACTA ÚNICA EUROPEA, EL TRATADO DE NIZA Y EL TRATADO DE LISBOA: SUS CONTRIBUCIONES A LA LEGISLACIÓN AMBIENTAL COMUNITARIA Y SU INFLUENCIA EN LA ATRIBUCIÓN DE COMPETENCIAS EN MEDIO AMBIENTE}

El marco legal básico de acción ambiental vino a reflejarse verdaderamente en los tratados desde el Acta Única Europea (AUE) de febrero de 1986, que entró en vigor el 1 de julio de 1987, siendo la culminación de varios años de trabajo y debate para profundizar en el proceso de integración europea ${ }^{45}$. El AUE introdujo un nuevo título en el Tratado de las Comunidades Europeas (TCEE), denominado «Medio Ambiente», y que comprendía los artículos 130R, 130S, y 130T. Entre sus principios (según el artículo 130R, apartado 1. ..) destacan: el carácter preventivo de las actuaciones medioambientales ${ }^{46}$; y como consecuencia de este principio, el principio de la correc-

43 Muñoz de Bustillo, R. y Bonete, R., Introducción a la Unión Europea: un análisis desde la economía. Madrid. Editorial Alianza, 3. ${ }^{a}$ edición revisada y aumentada, 2002; pág. 299.

44 El 13 de diciembre de 2007 se firmó en la capital de Portugal, el Tratado de la Unión que ya es conocido como el Tratado de Lisboa (TL), el cual tras el período de ratificación entró en vigor el 1 de diciembre de 2009. Se trata del nuevo TUE y el Tratado de Funcionamiento de la Unión Europea (TFUE) que ha sustituido al TCE. El TL ha mantenido parte de las novedades que aportaba la fallida Constitución Europea en el ámbito del medio ambiente. Consúltese «In depth: The Treaty of Lisbon - Implications for the Environment»: http://www.europarc.org/news/in-depth-thetreaty

${ }_{45}$ El AUE supuso la primera modificación de los tratados fundacionales: CECA, EURATOM y CEE.

46 Se trata del "principio de prevención», recogido en la "Declaración de Estocolmo» ya mencionada, pero que incluso se encontraba ya recogido en convenios anteriores, como es el caso de la "Convención sobre la Conservación de la Fauna y la Flora en su Estado Natural» (firmada en 1933 y que ya no está en vigor), cuyos objetivo era la preservación de «áreas» (llamándolas "protegidas») como método eficiente de protección real de la fauna silvestre.

Este principio está presente en nuestro ordenamiento comunitario y presume que un Estado debe prevenir daños ambientales adoptando las medidas preventivas que sean necesarias, ante un riesgo de daño cierto que ya se conoce, en lugar de esperar y restaurar a posteriori las áreas contaminadas.

Véase el AUE en el DOCE L 169 de 29 de junio de 1987. 
ción en la fuente de los perjuicios causados al medio ambiente (para mayor eficiencia y acercamiento al origen de los daños, así como en la prevención de su extensión); el principio de que quien contamina paga, es decir, la obligación de reparar y compensar cuando el daño ambiental ya se ha producido, (la aplicación de quien contamina paga es subsidiaria frente a la importancia adquirida por el principio preventivo $)^{47}$; y por último, el principio de la transversalidad o conexión (acercando la protección medioambiental al resto de políticas comunitarias).

Los objetivos eran: "Conservar, proteger y mejorar la calidad del medio ambiente; contribuir a la protección de la salud de las personas; y garantizar una utilización prudente y racional de los recursos naturales», y quedaron plasmados en el art. 130R, apartado 2. ${ }^{048}$.

Por otra parte, los artículos $130 \mathrm{~S}$ y $130 \mathrm{~T}$ animaban a una cooperación entre los EEMM y la CEE; quedando establecida una política de mínimos, admitiendo en el art. 130T la posibilidad de que los EEMM establecieran una mayor protección (siempre y cuando las medidas fueran compatibles con el AUE).

Asimismo, el artículo 100A, apartado 4. ${ }^{\circ}$ del AUE se refería a que «el Consejo podría, por mayoría cualificada, adoptar medidas de armonización /.../ en el ámbito de normativa ambiental, para un Estado miembro las aplicara en sus disposiciones nacionales, pero éste a su

47 Los principios medioambientales se perfeccionaron como consecuencia de la Conferencia de NNUU celebrada en Río de Janeiro en 1992 -ya mencionada- dando un paso más con el «principio de precaución medioambiental» recogido como principio 15, por el cual «los Estados deberán adoptar medidas eficaces para evitar peligros o daños ambientales graves o irreversibles, aún cuando no exista certeza científica absoluta sobre su existencia».

Tradicionalmente, los Estados que querían se adoptaran determinadas medidas protectoras, debían probar de manera indiscutible el peligro y la urgencia de las medidas deseadas (según el principio de prevención). A raíz del principio de precaución, este criterio tradicional sobre la carga de la prueba se invirtió. No obstante, su aplicación real está siendo muy escasa y sin duda habrá que esperar a una mayor conciencia en los asuntos medioambientales.

48 Más tarde, el «Tratado de la Unión Europea» (pactado en Maastricht y firmado en febrero de 1992), añadiría un cuarto objetivo de "fomentar medidas a escala internacional destinadas a hacer frente a los problemas regionales o mundiales del medio ambiente». Además, otra modificación de importancia del Tratado de Maastricht (1992) es que el artículo 130S contempla un nuevo apartado (quinto) que establece que, "sin perjuicio del principio quien contamina paga, cuando una medida adoptada implique costes que se consideren desproporcionados para las autoridades públicas de un Estado miembro, el Consejo establecerá, en el propio acto de adopción de dicha medida, las disposiciones adecuadas en forma de excepciones de carácter temporal y/o el apoyo financiero con cargo al Fondo de Cohesión.» Véase la versión del Tratado de Maastricht en el Diario Oficial de la CEE: DOCE C 191 de 29 de julio de 1992. 
vez podría elevar sus razones a la Comisión» por lo cual, la protección medioambiental era únicamente exigible, dijéramos, "limitadamente». Se continuaba sin dar paso a la elaboración de una política global y obligatoria comunitaria en la materia, pues cuando en el artículo 100, apartado $1 .^{\circ}$, se refería a la aproximación de disposiciones legales, reglamentarias y administrativas nacionales, sólo hacía mención a armonizaciones específicas y sectoriales ${ }^{49}$ que tuvieran por objeto el establecimiento y funcionamiento del mercado interior (ni siquiera se refería directamente al medio ambiente).

Los artículos 101 y 102 del TCEE completaban esa aproximación de normativas nacionales y la comunitaria, pero siempre podían aparecer distorsiones. Ante esta insuficiencia de medios jurídicos comunitarios para elaborar una política ambiental propia, no es de extrañar -como ya expresé- que fuera el Parlamento Europeo la institución precursora y que más se ocupara del tema ${ }^{50}$.

El artículo 130S del Acta introdujo la regla de la unanimidad en el seno del Consejo (en lo que a la acción que la CEE debiera emprender en materia medioambiental) a propuesta de la Comisión y previa consulta al Parlamento Europeo y al Comité Económico y Social ${ }^{51}$.

El Tratado de Niza firmado el 26 de febrero de $2001^{52}$ (en vigor hasta finales de noviembre de 2009) sentó la base para el establecimiento de las misiones de la Dirección General de Medio Ambiente, entre las que han destacado: «la utilización prudente y justa de los recursos naturales, la mejora de la calidad de vida, el aumento de la eficiencia medioambiental y la preservación de los derechos de las fu-

49 Ob. cit. Nascimbene, B., Ambiente (Tutela dell'), Diritto Comunitario, pág. 276.

50 En efecto, en distintas ocasiones, como es el caso de los informes Jahn, de 15 de diciembre de 1971, doc. 181/71, y de 14 de abril de 1972, doc. 9/72, en nombre de la Comisión Social y Sanitaria; informe Armengaud, de 17 de abril de 1972, doc. 15/72, en nombre de la Comisión Jurídica, e informe Alber de 26 de junio de 1981, doc. 1-276/81, en nombre de la Comisión de Medio Ambiente, el Parlamento fue poniendo de relieve la insuficiencia de disposiciones de índole ambiental y de salud pública.

51 El recurso a la unanimidad en el voto se ha podido interpretar como un temor por parte de ciertos EEMM de que se produjera una repercusión mayor de este derecho en los distintos sectores industriales y el coste económico que ello pudiera llevar consigo. Véase SANDS, Philippe; Principles of International Environmental Law. Capítulo "European Community Environmental Law», págs. 742-745. Cambridge,

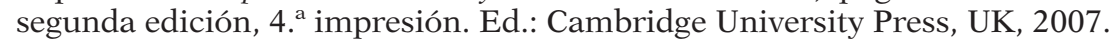

52 Véase el Tratado de Niza en el Diario Oficial C 80 de 10 de marzo de 2001: http://eur-lex.europa.eu/es/treaties/dat/12001C/htm/12001C.html 
turas generaciones». La base jurídica que me interesa especialmente señalar se refiere a los artículos 94 y 95 sobre la armonización del mercado en lo que respecta a los aspectos ambientales del mercado interior $^{53}$. Los EEMM no podrían adoptar o mantener en ese ámbito normas propias al margen de las disposiciones comunitarias, a menos que obtuvieran una autorización precisa de la Comisión conforme a los requisitos de los apartados 4, 5 y 6 del artículo 95 (ya me referí a esta autorización de la Comisión en los comentarios del AUE):

- El apartado $4 .^{\circ}$ de dicho artículo establecía que «tras la adopción por la Comunidad de una medida de armonización, el Estado miembro puede mantener disposiciones nacionales relacionadas con la protección del medio ambiente, si lo estima justificado por alguna razón importante relacionada con la protección medioambiental».

- El apartado 5. ${ }^{\circ}$ expresaba que «también los EEMM pueden adoptar nuevas disposiciones nacionales al margen de las disposiciones de armonización, sólo en el caso de que concurran las siguientes condiciones:

- Que sean disposiciones basadas en novedades científicas relativas a la protección del Medio Ambiente.

- Que estén justificadas por un problema específico en dicho EEMM, problema surgido con posterioridad a la adopción de la medida de armonización.

- Que tanto la medida tomada como la justificación sean comunicadas a la Comisión.

- Por último, el apartado 6. ${ }^{\circ}$ exigía «que las disposiciones nacionales sean aprobadas por la Comisión».

El título de Medio ambiente de Niza constaba de tres artículos: 174, 175 y 176, siendo el primero de ellos el que establecía los objetivos de la $\mathrm{CE}$ en materia de medio ambiente. Además, esta disposición afirmaba que la política de la Unión en esta materia debe fundarse en el principio de precaución, es decir, que a falta de certeza científica, cuando una evaluación científica previa considere «la existencia de riesgo de que se produzcan consecuencias poten-

53 El art. 95 del TCE de Niza corresponde ahora con el art. 114 del TFUE del Tratado de Lisboa (TL). El art. 94 del TCE de Niza, corresponde al art. 115 del TFUE del TL, y, el art. el 116 del TFUE del TL es el antiguo art. 96 del TCE. TL: :PDF

http://eur-lex.europa.eu/LexUriServ/LexUriServ.do?uri=OJ:C:2010:083:FULL:ES 
cialmente nefastas para el medio ambiente o la salud», podrán adoptarse medidas para evitar la realización de la acción humana que lo produciría $^{54 .}$

Hoy en día, más de 400 instrumentos legales comunitarios (principalmente directivas y reglamentos) -establecidos a lo largo de más de 40 años- cubren la práctica totalidad de los sectores del medio ambiente $^{55}$. Además, es de subrayar que la normativa medioambiental vigente en los EEMM, en casi un 85\%, tiene su origen en los contenidos de la legislación comunitaria. Dato que considero de gran interés.

Debido al carácter transversal que reviste la protección del medio ambiente, la UE puede y suele adoptar «medidas que tienen su base en otros títulos competenciales». Esto lo hemos visto con el artículo 37 del TCE (en vigor hasta noviembre de 2009) con respecto a la política agrícola común; pero también lo hemos tenido presente con las medidas adoptadas para la aproximación o armonización de las legislaciones nacionales a efectos de la consecución del mercado común sobre la base del ya mencionado art. 95 del TCE (antiguo art. 100A del AUE, y ahora, el art. 114 del TFUE del TL); o igualmente, ese carácter transversal se observa en medidas que han sido adoptadas en el ámbito de la política común de pesca.

En la competencia normativa medioambiental de la UE destaca, como ya hemos visto, el peso relativo de las «directivas» frente al resto de otros instrumentos legislativos: los reglamentos, las decisiones y las recomendaciones ${ }^{56}$. El Prof. Julio García nos indica que "el predominio de las directivas se explica muy a menudo en base al principio de subsidiariedad, ello tiene que ver con el respeto que imponía el hasta ahora artículo 174.3 del TCE, de tener en cuenta la diversidad de las condiciones medioambientales en las distintas regio-

54 Fue uno de los principios estrella de la Cumbre de Río en 1992, y al que ya me he referido.

55 Todas estas normas son los instrumentos de ejecución de esa política. Decía el artículo 175.4 del TCE «...los Estados miembros tendrán a su cargo la financiación y la ejecución de la política en materia de medio ambiente». /.../ «La política ambiental es una actividad pública de gestión, impregnando todos los ámbitos comunitarios. /.../» Párrafo extraído de la pág. 87 del libro de Moreno Molina, Á. M. Derecho comunitario del medio ambiente: marco institucional, regulación sectorial y aplicación en España. Madrid. Ed.: Marcial Pons, 2006.

56 Artículo redactado por García BuRgues, J. «Derecho Europeo Medioambiental: La protección del medio ambiente en la UE», págs. 45-74. Revista n. ${ }^{\circ} 134$ Estudios de Derecho Judicial «Derecho europeo medioambiental: La protección del medio ambiente en la Unión Europea: Los aspectos críticos». Ed.: Consejo del Poder judicial. Director: Antonio Vercher Noguera. (2007). 
nes de la Unión. Además, los reglamentos son directamente aplicables y obligatorios, mientras las directivas son más flexibles y cercanas, son vinculantes en cuanto a los objetivos a alcanzar, y su aplicación por parte de los EEMM exige un acto legislativo de transposición por parte del Estado miembro concernido ${ }^{57}$.

Según el principio de subsidiariedad ${ }^{58}$ del artículo 5 del TCE de Niza (hasta que entrara en vigor el TL el 1 de diciembre de 2009), la Unión únicamente interviene en la medida en que los objetivos del fin pretendido no puedan ser alcanzados de manera eficiente por los EEMM a nivel nacional y regional, y por consiguiente, puedan lograrse mejor a nivel comunitario. Este principio no afecta a la distribución de competencias entre la UE y los EEMM, es un principio que ofrece una orientación evolutiva de cómo han de ejercerse las competencias a nivel comunitario, por tanto, es dinámico y se aplica en un ámbito local cercano al ciudadano para ofrecer una mayor eficacia en la aplicación de la normativa comunitaria. El principio había sido ya formulado en el Tratado de Maastricht de 1992 de forma limitadora en cuanto a las competencias de la Comunidad se refiere, por ello, su adaptación al ordenamiento jurídico ha generado siempre un intenso debate doctrinal ${ }^{59}$.

Según la Dra. Mariola Urrea, se trata de «un principio que rige el modo de ejercicio de la competencia; no sirve para delimitar o atribuir competencias, sino que persigue racionalizar ese ámbito difuso y demasiado elástico de la competencia comunitaria compartida. Nos dice hasta dónde debe llegar la UE cuando aprueba normas» ${ }^{60}$.

${ }^{57}$ Ibidem, Revista $n .^{\circ} 134$ "Derecho europeo medioambiental (...)», el párrafo ha sido extraído de la pág. 14.

${ }_{58}$ Fue Giscard d'Estaing quien propuso en su día la inclusión de un artículo en los respectivos tratados CEE, CECA y Euratom, que formulara este principio en términos de eficacia, para poder trascender la operatividad simple de la CEE y de los EEMM separadamente. Véase el «Report of the Committee on Institutional Affairs on the Principle of the Subsidiariety», de 31 de octubre, 1990. Session Documents of the European Parliament; versión inglesa, págs. 4-5.

59 Sobre el principio de subsidiariedad, véase también FONSECA MORILLO, F.: «Legitimidad democrática: el principio de Subsidiariedad», Revista Electrónica Jurídica (REJ), n. ${ }^{\circ} 11$, dic. 1992; pág. 11.

60 Véase el documento redactado por Mangas Martín, A., «La Distribución de competencias en la UE y el principio de subsidiariedad» publicado en Internet por la Fundación Manuel Giménez Abad de Estudios Parlamentarios y del Estado Autonómico. Parlamento de Navarra. Véase:

http://www.idpbarcelona.net/docs/recerca/dretue/docs/pdf/subsid_workinpapers/1_mangas_distribucion_competencias.pdf

En la pág. 11 del documento mencionado expresa la Catedrática MANGAS: «Para saber si la Unión actúa de conformidad con este principio y no se excede legislando e invadiendo competencias internas (locales, regionales y estatales) debemos examinar la 
De la misma forma, la actuación comunitaria debe someterse al principio de proporcionalidad ${ }^{61}$, por el que «ninguna acción de la UE excederá de lo necesario para alcanzar los objetivos que se pretendan». De acuerdo con el Protocolo de actuación comunitaria debe ser lo más sencilla posible, y ello, supone que al elegir los instrumentos normativos, las directivas se hayan encontrado más adecuadas frente a los reglamentos. A su vez, las directivas marco, son preferidas a las detalladas, lo que incide en la posibilidad de exigir una mayor responsabilidad a los EEMM a la hora de aplicar la normativa comunitaria.

Tras el Tratado de Maastricht, a instancias del Consejo Europeo de Lisboa de 1992, la Comisión Europea comenzó a reexaminar diversos sectores del Derecho Comunitario para adaptarlos a los dos principios mencionados. En el ámbito del medio ambiente, esta iniciativa se centró en la normativa comunitaria de protección de las aguas y de la atmósfera, donde el principio de proporcionalidad impulsó la revisión de algunas directivas como ya he señalado más arriba, así como la reorganización de estos sectores medioambientales a través de nuevas directivas marco ${ }^{62}$.

En virtud de este principio, la Comisión ha favorecido durante los últimos 30 años, medidas de carácter no vinculante que dejan una mayor libertad a los EEMM. Ejemplo de ello son los «acuerdos voluntarios con la industria» propugnados por el «Quinto Programa de Acción Comunitaria en Medio Ambiente», y posteriormente, por el «Sexto Programa» 33 .

norma comunitaria conforme a tres criterios cumulativos: la dimensión comunitaria del problema, la necesidad de actuar y la mayor eficacia de la respuesta. Si las Instituciones europeas adoptan un acto en ámbitos de competencia compartida que no respeta cualquiera de los tres criterios aludidos se podrá pedir su anulación al Tribunal de Justicia de la UE; así los EEMM (Gobiernos, y Parlamentos nacionales) y las regiones, a través del Comité de las Regiones, se pueden defender frente a incursiones ilegítimas de la Unión. También los particulares afectados directamente por una norma u acto comunitario, /.../»

61 Consúltense la Sentencia del TJCE: de 14 de julio de 1998. Asunto: 284/95 Safety Hitech Srl. (REC.-4301), y la Sentencia del TJCE de 29 de abril de 1999. Asunto C-293/97, Standley y otros. (REC. I-2603).

62 Recuerdo la -ya mencionada- Directiva 2000/60/CE del Parlamento Europeo y del Consejo de 23 de octubre de 2000, conocida por las siglas DMA, por la que se estableció un marco comunitario de actuación en el ámbito de la política de aguas.

63 Sobre los Programas Quinto y Sexto, consúltese la «Comunicación de la Comisión al Consejo y al Parlamento Europeo relativa a los Acuerdos sobre Medio Ambiente». Bruselas, 27.11.1996, en la dirección on line: http://eur-lex.europa.eu/ LexUriServ/LexUriServ.do?uri=COM:1996:0561:FIN:ES:PDF

A continuación extraigo algunas afirmaciones de la Comunicación: 
Siguiendo la línea de las competencias compartidas en el ámbito medioambiental, los EEMM en ausencia de normativa comunitaria, naturalmente son competentes para legislar en materia de protección de medio ambiente, siempre y cuando se respeten las disposiciones y principios de los Tratados comunitarios. Pero tan pronto la Unión emite una legislación medioambiental específica -reitero- los EEMM deben respetarla procediendo a adecuar sus propias normativas nacionales si ello fuera preciso. Las disposiciones jurídicas de los EEMM deben de ser siempre compatibles con los Tratados comunitarios, en la actualidad, con el TL en vigor: TUE, TFUE, sus Declaraciones, sus Protocolos y sus Anexos.

Indudablemente, los EEMM siempre podrán transponer las normativas comunitarias (generalmente «directivas» en este ámbito de medio ambiente) con un amplio margen de libertad en cuanto a opciones o medios se refiere, siempre y cuando a través de ellos se alcancen los objetivos pretendidos por la normativa comunitaria.

El Tratado Constitucional que no llegó a ser ratificado por todos los EEMM en 2004, regulaba las competencias de la Unión en el título III (art. I-11 a I-18); y el artículo I-14 se ocupaba de los ámbitos de competencia compartida de la Unión con los EEMM, entre los que se encontraba el medio ambiente. Además, en el

«/.../ En las consideraciones generales relativas a los acuerdos sobre medio ambiente en tanto que instrumento de actuación, se analizan los beneficios y problemas críticos.

Por el creciente interés por los acuerdos sobre política ambiental y el uso de los mismos /.../ para que el desarrollo resulte sostenible es preciso que los sectores industriales afectados pasen de la reacción a la acción. /.../ se describen esquemáticamente los beneficios potenciales de las medidas voluntarias.

La iniciativa se ajusta a la estrategia señalada en el Quinto Programa de Medio Ambiente, como lo ha confirmado recientemente la Comisión en su propuesta de revisión de dicho programa.

Los acuerdos con la industria constituyen un instrumento versátil que puede emplearse a nivel regional, nacional, comunitario o internacional. Hasta el momento, han sido fundamentalmente acuerdos no vinculantes y voluntarios, pero recientemente, algunos Estados miembros han optado por darles un carácter más formal y vinculante.

Los acuerdos sobre medio ambiente pueden hacer que se apliquen medidas eficaces anticipándose a la legislación y, por tanto, que se reduzca el volumen de iniciativas reglamentarias y administrativas. Por esa razón, la presente iniciativa está relacionada con la labor que realiza la Comisión para simplificar la legislación comunitaria y mejorar su calidad.

Los acuerdos pueden utilizarse como complemento de la legislación y pueden ser una herramienta adecuada de aplicación. Los acuerdos de carácter vinculante son un instrumento eficaz y apropiado de conseguir los objetivos generales establecidos en las directivas comunitarias, especialmente la aplicación de los programas de reducción.

A nivel comunitario, mediante dichos acuerdos la Comisión puede ocuparse de cuestiones medioambientales sin necesidad de recurrir a los instrumentos reglamentarios tradicionales. /.../» 
artículo I-13, dedicado a las competencias exclusivas de la Unión, se enumeraban una serie de ámbitos vinculados con el medio ambiente, como eran, por ejemplo, la introducción de la conservación de los recursos biológicos marinos dentro de la política pesquera común ${ }^{64}$. Los artículos 174,175 y 176 del Tratado de Niza de 2001 pasaron a ser en el texto de la fallida Constitución Europea los artículos III.233 y III.234 en la sección 5. ${ }^{\text {, }}$, denominada «de Medio Ambiente».

Con respecto al Tratado de Lisboa (TL), la UE dispone de las competencias que los EEMM le asignan en el Tratado, estoy refiriéndome al principio de atribución ya señalado más arriba. Por lo demás, el resto de competencias no atribuidas siguen perteneciendo a los EEMM. El Dr. Martín y Pérez de Nanclares insiste en la importancia de este principio en el TL, señalando particularmente al art. 5, 2. ${ }^{\circ}$, que indica "En virtud del principio de atribución, la Unión actúa dentro de los límites de las competencias que le atribuyen los Estados miembros en los Tratados para lograr los objetivos que éstos determinan. Toda competencia no atribuida a la Unión en los Tratados corresponde a los Estados miembros». Es decir, que la versión consolidada del texto del Tratado de la UE (TUE) del TL utiliza una formulación aún más restrictiva ${ }^{65}$ que la del artículo 5 del TCE de Niza, que disponía: "La Comunidad actuará dentro de los límites de las competencias que le atribuye el presente Tratado y de los objetivos que éste le asigna», y también esta versión es más restrictiva que de la del Tratado Constitucional que no llegó a ser ratificado.

En la misma línea, parece que el TL pudiera haber introducido un aspecto retrógrado en el artículo 48: «El Gobierno de cualquier EEMM, el Parlamento Europeo o la Comisión podrán presentar al Consejo proyectos de revisión de los Tratados. Estos proyectos podrán tener por finalidad, entre otras cosas, la de aumentar o reducir las competencias atribuidas a la Unión en los Tratados. El Consejo remitirá dichos proyectos al Consejo Europeo y los notificará a los Parlamentos nacionales».

Igualmente, el TL no es tan explícito como lo fuera el Tratado Constitucional, no incluye una lista de las competencias exclusivas de la UE y de las competencias que comparte con los EEMM, pareciera que el objetivo final fuera el de impedir que la Unión gane

64 Este artículo se hace eco de la doctrina del TJCE, ya en Sentencia de 5 de mayo de 1983, en un Asunto de la Comisión contra el Reino Unido, confirmando como competencia exclusiva de la CEE la adopción de medidas que se consideraran necesarias para la conservación de los recursos biológicos del mar.

65 Versión consolidada de 2010 del TUE:

http://eur-lex.europa.eu/LexUriServ/LexUriServ.do?uri=OJ:C:2010:083:0047:020 :es:PDF

(C) UNED. Revista de Derecho UNED, núm. 12, 2013 
competencias de los Estados, e incluso, por lo visto en el párrafo anterior, incluso permitirles que puedan desposeer a la Unión de las competencias ya transferidas, pudiendo de esta manera, recuperarlas $^{66}$. Asimismo, asistimos al refuerzo de la soberanía estatal y a la pérdida de atribuciones de la Unión, cuando con la Declaración n. 18 relativa a la delimitación de las competencias se nos recuerda que los EEMM ejercerán de nuevo una competencia que la UE haya dejado de ejercer, por ejemplo, en aplicación de los principios de subsidiariedad y proporcionalidad ${ }^{67}$.

Reforzando el control de estos principios, según el artículo 8 del Protocolo n. ${ }^{\circ}$ 2.: "el Tribunal de Justicia de la UE será competente para pronunciarse sobre los recursos por violación del principio de subsidiariedad, por parte de un acto legislativo, interpuesto con arreglo a los procedimientos establecidos en el artículo 263 del TFUE (...), el Comité de las Regiones también podrá interponer recursos contra actos legislativos para cuya adopción el TFUE requiera su consulta». Y la Declaración n. ${ }^{\circ} 42$ relativa al artículo 308 del TCE (art. 352 del presente TFUE en la versión consolidada del texto del TL) conocida como cláusula de flexibilidad, precisa: «que el principio de las competencias de atribución, no puede servir de base para ampliar el ámbito de las competencias de la Unión más allá del marco general que establecen las disposiciones de los Tratados en su conjunto, en particular aquellas por las que se definen las funciones y acciones de la Unión. Este artículo no podrá en ningún caso servir de base para adoptar disposiciones que tengan por efecto,... modificar los Tratados sin seguir el procedimiento que éstos fijan ...».

Un ejemplo más, lo tenemos en la Declaración $\mathbf{n} .^{\circ} \mathbf{2 4}$ relativa a «la personalidad jurídica de la $\boldsymbol{U E}$ » donde se confirma que «el he-

66 Véanse los comentarios al respecto en Martín y Pérez de Nanclares, J. (Coord.), El Tratado de Lisboa. La salida de la crisis constitucional, pág. 92. Jornadas de la Asociación Española de Profesores de Derecho Internacional y Relaciones Internacionales -AEPDIRI- celebradas en Madrid el 17 y 18 de diciembre de 2007. Ed.: Iustel, 1. ${ }^{a}$ edición, Madrid 2008.

67 «Cuando los Tratados atribuyan a la Unión una competencia compartida con los EEMM en un ámbito determinado, los EEMM ejercerán su competencia en la medida en que la Unión no haya ejercido la suya o haya decidido dejar de ejercerla. Esta última situación se plantea cuando las instituciones competentes de la Unión deciden derogar un acto legislativo, en particular para garantizar mejor el respeto constante de los principios de subsidiariedad y proporcionalidad. El Consejo, a iniciativa de uno o varios de sus miembros (representantes de los EEMM) y de conformidad con el artículo 241 del TFUE, podrá pedir a la Comisión que presente propuestas de derogación de un acto legislativo.»

Consúltese la dirección de Internet: http://www.eurogersinfo.com/espagne/actes808.htm 
cho de que la Unión Europea tenga personalidad jurídica no autorizará en modo alguno a la Unión a legislar o actuar más allá de las competencias que los Estados miembros le han atribuido en los Tratados».

Estas muestras, en las que insisto, evidencian una regresión en las atribuciones dadas a la Unión, ya sea en los procedimientos de toma de decisiones o en el reparto de competencias entre la Unión y los EMMM.

Por su parte, el TFUE como ya sabemos, recoge expresamente, junto a otros ámbitos, al medio ambiente como una competencia compartida entre la Unión y los EEMM en su art. 4; política, por desgracia, en la que los EEMM no parecen querer ceder más terreno ${ }^{68}$.

68 De hecho, en la práctica, y como muestra del comportamiento reticente de los EEMM a «delegar más competencias a la Unión en este ámbito» es muy ilustrativo el siguiente extracto de un texto de Hilario Domínguez, sobre lo acontecido en el Consejo de Ministros de diciembre 2007:

/.../ La Comisión presentó una Estrategia sobre suelos en septiembre de 2006, y con ella una propuesta de Directiva que constituye el instrumento y medida más importante para la aplicación de la citada Estrategia.

El Consejo ya sostuvo un debate de orientación en febrero de este año y los Ministros tuvieron la ocasión de manifestarse sobre el valor añadido de la Directiva, su solapamiento con otras normas legislativas ambientales y, como gran cuestión de fondo, sobre "la aplicación de los principios de subsidiariedad y proporcionalidad» que algunas delegaciones invocaron para no aceptar esta propuesta de Directiva (Reino Unido y Países Bajos no la aceptan, Alemania, Austria y Francia mantuvieron reticencias).

La propuesta de original de la Comisión en principio establecía las principales obligaciones siguientes:

En un plazo de 5 años los EE.MM deberán identificar las "áreas de riesgo» de su territorio donde hay evidencia o legítima sospecha de procesos de degradación de suelo l.../

Los EEMM elaborarán programas para las áreas de riesgo con objetivos, acciones, calendario de ejecución y costes estimados. /.../

Los EEMM deberán tomar medidas para limitar el depósito intencionado o no intencionado de substancias peligrosas, excepto las procedentes del aire y fenómenos de carácter inevitable. /.../

Los EEMM garantizarán que los lugares contaminados que aparecen en el inventario son restaurados /.../

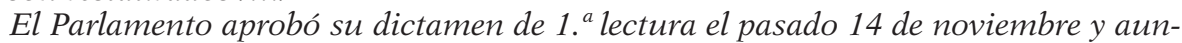
que el debate se desarrolló en condiciones difíciles, /.../ En el COREPER preparatorio, varias delegaciones (Alemania, Reino Unido, Francia, Países Bajos) solicitaron la retirada de este punto del orden del día del Consejo, anunciando que no estaban en condiciones de llegar a un acuerdo.

En el Consejo se plantearon las mismas dificultades que en el debate de orientación del Consejo de febrero.

A pesar de las sucesivas propuestas de compromiso, que la Presidencia presentó a lo largo de la jornada, y que cada vez aligeraban más un texto ya de por sí bastante suave, las citadas delegaciones insistieron en rechazarlas con diferentes argumentos, que de una forma u otra escondian las verdaderas razones de su 
Al mismo tiempo, se mantiene la obligación de integrar las exigencias de la protección del medio ambiente en la definición y en la realización de las políticas y acciones de la Unión en el art. 11 del TFUE (antiguo artículo 6 del TCE), me estoy refiriendo a la conocida «transversalidad medioambiental». En este sentido, destaca el papel del Parlamento Europeo como precursor de esta transversalidad y la acción de la Comisión.

En este sentido, considero relevante la Comunicación de la Comisión titulada "Colaboración para la integración-Una estrategia para la integración del medio ambiente en las políticas de la Unión Europea ${ }^{69}$ que fue presentada ante el Consejo Europeo de Cardiff en junio de 1998. Entonces se solicitó a todas las formaciones pertinentes del Consejo que establecieran sus propias estrategias para integrar el medio ambiente en sus respectivos ámbitos de actuación. Las nueve composiciones del Consejo que desarrollaron estrategias de integración en Cardiff fueron las que se ocupaban de: Asuntos Generales, Economía y Finanzas, Mercado Interior, Industria, Energía, Agricultura, Desarrollo, Pesca y Transporte. Sin embargo, lamentablemente, en el primer informe de evaluación del proceso de Cardiff presentado en 2004, se expresaba que «el proceso de Cardiff no había dado todos los resultados esperados ${ }^{70}$.

En estos últimos años, la integración de la política medioambiental ha alcanzado los avances más significativos en el ámbito de la po-

oposición. No deseaban que la Comunidad, a través de una norma legislativa, por inocua que fuera, adquiriese competencias en politicas de suelo.

Alemania, Países Bajos, Austria, Reino Unido y Francia votaron contra la propuesta. Los tres primeros señalando claramente su firme oposición a cualquier tipo de directiva comunitaria sobre el suelo. Reino Unido por considerar que a pesar de la suavidad del texto, resultaba demasiado "prescriptivo, oneroso y fuente de futuros litigios en los tribunales» y Francia por "defectos en la metodología y otros problemas técnicos». I.../

Suecia, Finlandia, Luxemburgo y Malta tenían dificultades, pero expresaron su disposición a llegar a un acuerdo a lo largo del Consejo. /.../

Como he indicado más arriba, se trata de un extracto del artículo de Domínguez Hernández, H.; "Consejo de Ministros de Medio Ambiente de la Unión Europea» (diciembre 2007); Revista Ambienta, enero 2008; págs. 56-57.

69 Esta Comunicación (COM (1998) 333) había sido publicada por la Comisión el 27 de mayo de 1998:

http://eur-lex.europa.eu/LexUriServ/LexUriServ.do?uri=COM:1998:0333: FIN:ES:PDF

70 Una declaración no vinculante aneja al Tratado de Ámsterdam (1997) comprometía, por primera vez, a la Comisión a llevar a cabo evaluaciones de impacto al presentar propuestas que pudieran tener repercusiones importantes sobre el medio ambiente. Consúltese el balance del proceso de Cardiff en el Trabajo de la Comisión $\operatorname{COM}(2004) 394$ final en Internet: http://eur- lex.europa.eu/smartapi/cgi/sga_doc?sma rtapi!celexplus!prod!CELEXnumdoc\&lg=es\&numdoc=52004DC0394 
lítica energética y en las cuestiones relacionadas con el CC, como ya hemos visto en el epígrafe segundo de este artículo. En este contexto, la Comisión publicó en marzo de 2011, su «Hoja de ruta hacia una economía hipocarbónica competitiva en 2050 „ ${ }^{71}$ buscando maneras rentables de hacer que la economía europea sea más respetuosa con el clima y consuma menos energía para lograr el objetivo de una reducción del $80 \%$ de las emisiones antes de 2050 .

\section{CONSOLIDACIÓN DE LAS FUNCIONES DE LOS PARLAMENTOS NACIONALES EN EL TRATADO DE LISBOA}

El Tratado de Lisboa ha añadido una sección titulada «Provisiones sobre los principios democráticos», en base a ello, reconoce y consolida las funciones de los parlamentos nacionales que, aunque por supuesto, no son instituciones de la Unión, desempeñan una labor importante en su funcionamiento, en un intento más de acercar la actividad institucional de la Unión a los ciudadanos europeos. Ello se remonta a 2006 con una Comunicación de la Comisión "Una agenda de los ciudadanos-Logrando resultados para Europa». En primer lugar, ese acercamiento siempre ha estado presente a través del Parlamento Europeo, siendo precisos sus dictámenes a la Comisión en las iniciativas y control medioambientales en lo que respecta al interés de este artículo, ahora con más claridad en el TL. En segundo lugar, el TL reconoce un mayor papel de los Parlamentos nacionales durante el proceso de codecisión ${ }^{72}$, así, el artículo 5, 3, párrafo $\mathbf{2 .}^{\circ}$ del TUE expresa «que los Parlamentos nacionales velarán por el respeto del principio de subsidiariedad con arreglo al procedimiento establecido en el mencionado Protocolo», (se refiere al Protocolo n. ${ }^{\circ} \mathbf{1}$ «Sobre el cometido de los Parlamentos nacionales en la UE»).

También el artículo 12 del TUE expresa que los Parlamentos nacionales contribuirán activamente al buen funcionamiento de la Unión, por ello «deben ser informados de los actos legislativos en marcha, pues participan en el control del principio de subsidiariedad

71 Véase la Comunicación emitida en Bruselas el 8 de marzo de 2011, (COM (2011) 112 final): http://eur-lex.europa.eu/LexUriServ/LexUriServ. do?uri=COM:2011:0112:FIN:ES:PDF

72 Véase "The role of national parliaments in regional policy under the Treaty of Lisbon», Dr. KRAMER, Esther, del «Policy Department Structural and Cohesion Policies». Publicado por el Parlamento Europeo en Bruselas en 2010. Este documento está disponible en Internet en: http://www.europarl.europa.eu/studies 
(como expresé en el párrafo anterior), /.../ Participarán en la revisión de los Tratados ${ }^{73}$, serán informados de las solicitudes de adhesión y participarán en la cooperación parlamentaria entre Parlamentos nacionales y el Parlamento Europeo».

Del mismo modo, los Parlamentos nacionales podrán manifestar su parecer desde la fase inicial de una propuesta, antes de que ésta sea estudiada a fondo en el Parlamento Europeo y el Consejo de Ministros. De hecho, «el control previo de los Parlamentos nacionales sobre toda la legislación de la Unión será reforzado dado que éstos recibirán con tiempo suficiente todas las propuestas legislativas europeas con el fin de que puedan debatirlas con sus ministros antes de que el Consejo adopte una posición y obtendrán, asimismo, el derecho de exigir un nuevo examen de una propuesta si consideran que no se cumple el principio de subsidiariedad ${ }^{74}$.

Pero además, «en la nueva redacción del artículo 5,3 del TUE, explícitamente se incluye a los distintos niveles de gobierno -y entre ellos a las regiones-en la definición del principio de subsidiariedad, y se supera así la visión del principio que limitaba su alcance a las relaciones entre la Unión y sus EEMM» ${ }^{75}$.

Por último, también los artículos 7 y siguientes del Protocolo n. ${ }^{\circ} 2$ «Sobre la aplicación de los principios de subsidiariedad y proporcionalidad» introducen matices que suponen un auténtico control por parte de los Parlamentos nacionales en el funcionamiento legislativo de la Unión: "Las instituciones de la UE tendrán en cuenta los dictámenes motivados dirigidos por los Parlamentos nacionales o cualquiera de las cámaras de un Parlamento nacional». "Una vez informadas las Instituciones (o, en su caso, el grupo de Estados) pertinentes de los dictámenes enviados por los parlamentos nacionales, se inicia la posibilidad de bloqueo de la iniciativa./.../ ${ }^{76}$

73 Por supuesto, también en aquellas revisiones de tratados y acuerdos que tengan que ver con la protección ambiental o el desarrollo o cooperación en medio ambiente con terceros países.

74 Véase la Resolución del Parlamento Europeo, 20 de febrero de 2008 sobre el Tratado de Lisboa (2007/2286(INI)).

75 Morata, Francesc; "Subsidiariedad, regiones y Unión Europea». Cuadernos Europeos de Deusto, $n .^{\circ}$ 35, Bilbao, 2006; págs. 73-94.

76 Ob. cit., MARTín y PÉREZ De NANCLARES, J. (Coord.) El Tratado de Lisboa. La salida de la crisis constitucional, pág. 255. Véase también el capítulo: «Parlamentos nacionales y ciudadanía en el funcionamiento institucional de la Unión» por la Prof., Cervell Hortal, M. ${ }^{\mathrm{a}}$ José, págs. 250-265.

Se puede consultar el Protocolo 2. ${ }^{\circ}$ del TL en la dirección de Internet: :PDF

http://eur-lex.europa.eu/LexUriServ/LexUriServ.do?uri=OJ:C:2010:083:FULL:ES 
He de subrayar que el número de dictámenes que los Parlamentos nacionales han remitido a la Comisión Europea han aumentado drásticamente desde la entrada en vigor del TL. En este sentido, la Comisión ratifica que ahora los Parlamentos nacionales están ejerciendo sus responsabilidades en el procedimiento decisorio de la Unión interviniendo más activamente en todas las políticas comunitarias, ${ }^{77}$ y por tanto, las políticas de energía y medio ambiente, no son una excepción ${ }^{78}$ " Se ha ampliado el plazo de emisión del informe de los parlamentos nacionales previsto al efecto a ocho semanas (en lugar de seis), a la vez que se altera el valor jurídico de los dictámenes negativos emitidos por los parlamentos nacionales en el nuevo mecanismo de alerta temprana» ${ }^{79}$.

\section{CONSIDERACIONES FINALES}

En primer lugar, recordar que los Estados de Europa siempre han representado un papel ascendiente indudable en la protección

77 «En 2010, los Parlamentos nacionales presentaron 387 dictámenes sobre una extensa gama de asuntos, lo que supuso un aumento de casi el $60 \% . » / . .$. . Léase el comunicado de prensa de la Comisión Europea de 10 de junio de 2011: http://prensaeuropa.es/press-releases/los-parlamentos-nacionales-recogen-el-envite

78 Consúltese el «Informe anual 2011 de la Comisión sobre las relaciones entre la Comisión europea y los Parlamentos nacionales». Por ejemplo, la Comunicación $\operatorname{COM}(2011) 370$ sobre Eficiencia Energética, atrajo nada menos que hasta 12 aportaciones de los Parlamentos nacionales al respecto y además: «National Parliaments agreed that achieving the $20 \%$ primary energy saving target was a key objective under the Europe 2020 Energy and Environmental Strategy.» (Los Parlamentos nacionales estuvieron de acuerdo en ahorrar un $20 \%$ de energía como objetivo de la estrategia energética y medioambiental para 2020»).

http://eur-lex.europa.eu/LexUriServ/LexUriServ.do?uri=COM:2012:0375: FIN:EN:PDF

${ }_{79}$ «A principios de abril del año 2010, la Comisión Mixta para la Unión Europea del Parlamento español -en adelante Comisión Mixta-empieza a remitir a los parlamentos de las comunidades autónomas las iniciativas legislativas comunitarias para que realicen la evaluación del principio de subsidiariedad, de acuerdo con las previsiones que incorpora el Tratado de Lisboa del 13 de diciembre de 2007, el denominado Sistema de Alerta Temprana (SAT), también llamado de alerta rápida o precoz.» (...)

«En lo que se refiere al caso español, al no contar con una cámara de representación territorial puramente autonómica, la voz de las comunidades autónomas -o con más precisión, de las cámaras parlamentarias autonómicas-queda diluida en un procedimiento intermediado o protagonizado por la Comisión Mixta en el que esta tiene prácticamente todo el poder de decisión. En la reforma de la misma para su adaptación a las nuevas misiones que atribuye el Tratado de Lisboa a los parlamentos, se ha perdido una buena oportunidad para haber establecido procedimientos de obligatoriedad en cuanto a la incorporación de la posición autonómica.» (...) Ambos párrafos han sido extraídos del interesante artículo de DE CASTRO RUANO, José Luis, «El sistema de alerta temprana para el control de la subsidiariedad: su aplicación por el Parlamento Vasco» de la Revista CIDOB d'afers internacionals, n. ${ }^{\circ}$ 99, (septiembre 2012); págs. 93-111. 
ambiental en el ámbito internacional; así, cuando en octubre de 1950 en París surgió la «Convención Internacional para la Protección de las Aves», (cuyo principal objetivo era proteger a las aves en estado salvaje y en época de cría), únicamente Estados europeos -todavía la $\mathrm{CE}$ no había nacido- firmaron dicha convención, cuando sin embargo, dicho acuerdo estaba abierto a todos los Estados del mundo. Sobre otras muestras precursoras de la UE en medio ambiente, me remito al primer epígrafe del presente artículo.

En segundo lugar, como puede comprobarse en los dos últimos epígrafes de este artículo, no podemos pasar por alto que el TL ha producido una regresión en la atribución de competencias a la Unión. Ello repercute directamente en la política medioambiental. De hecho, ante el doble desafío, no sólo medioambiental, sino también de necesidad energética que vivimos en la actualidad, se debería haber aprovechado el TL para reforzar la política comunitaria de medio ambiente, dado que los EEMM, aunque basen la mayor parte de su normativa medioambiental en la comunitaria, queriendo o sin querer, se siguen rigiendo por intereses propios. Así, cuando en 2007 la UE creó una agenda para cumplir con las cuotas de utilización de energías renovables, la exigencia por parte de la Comisión Europea de armonizar mecanismos para apoyo de las renovables y así reducir el $\mathrm{CO}_{2}$, elló chocó con la actitud, pudiéramos decir, «soberanista» de Polonia y de la República Checa ${ }^{80}$.

En tercer lugar, la nueva posición del Parlamento Europeo y los Parlamentos nacionales, avala un mayor control de las políticas comunitarias, y si bien ello ralentiza las «iniciativas», sin embargo, garantiza en un sentido positivo, una mejor implementación de la legislación comunitaria, en este caso, la medioambiental.

Por último, en la actualidad, con motivo de la crisis económica y financiera mundial que comenzara en 2007 y que está castigando con especial dureza a algunos EEMM, la exigencia medioambiental comunitaria se ha reducido a sus mínimos en la práctica, y ello, aún cuando nos queramos seguir exhibiendo como paladines del respeto ambiental ante el resto del mundo. De hecho, ya en las últimas cumbres sobre el Cambio Climático para encontrar un acuerdo post Kyoto, se ha evidenciado una pronunciada falta de unidad en el pensamiento y acción comunitarios. En la Cumbre del CC de Copenhague

80 Esta evidencia se desprende de la lectura del documento "The European Commission has told Poland and the Czech Republic to significantly lower the $\mathrm{CO}_{2}$ limits imposed on their industry for 2008-2012, sparking a row with Warsaw and Prague.»: http://www.euractiv.com/node/188317/reference 
en 2009, quedó patente que «la UE fue incapaz de asumir un papel de liderazgo en la lucha contra el cambio climático y que ni siquiera participó en las negociaciones finales con los Estados Unidos, China, la India, Brasil y Sudáfrica sobre el borrador final del Acuerdo» ${ }^{81}$. La falta de coherencia de la Unión ha sido exhibida de nuevo al año siguiente en Cancún ${ }^{82}$, en Durban en $2011^{83}$ y en Doha en $2012^{84}$. Pese a estos argumentos, en nuestra acción exterior queremos seguir mostrándonos como los ascendientes de un medio ambiente saludable ante nuestros vecinos, muestra de ello es un Dictamen exploratorio de 2011 del Comité Económico y Social Europeo sobre «La promoción de las energías renovables y la política europea de vecindad: la situación euro mediterránea» ${ }^{85}$.

Concluyendo, por una parte, podemos estar orgullosos por el camino recorrido por la UE en el ámbito del medio ambiente, pero por otra parte, no podemos ser tan inocentes como para olvidar que los intereses nacionales miran a muy corto plazo, y por ello, el ámbito medioambiental europeo está sufriendo en nuestros días un detrimento de atención en aras de la maltrecha situación económica, si bien al principio de la crisis, y considero que muy acertadamente, el

81 Párrafo extraído de la» Resolución del Parlamento Europeo, 10 de febrero de 2010, sobre los resultados de la Conferencia de Copenhague sobre el Cambio Climático» (COP 15).

82 Sobre Cancún, véase el artículo de Lara LÁZARO «Cancún: anclando Copenhague y salvando el proceso para salvar el clima ... quizás mañana» aparecido en la Revista ARI en enero 2011 del Real Instituto Elcano. Área de Economía y Comercio internacional:

http://www.realinstitutoelcano.org/wps/wcm/connect/d5691300457c5351883fcf5e 7489e10f/ARI12-2011_Lazaro_Cancun_Copenhague_cambio_climatico.pdf?MOD=AJ PERES\&CACHEID $=\bar{d} 5691300457 \mathrm{c} 5351883 \mathrm{fcf} 5 \mathrm{e} 7489 \mathrm{e} 10 \mathrm{f}$

83 Véase el artículo «Europa espera recuperar el liderazgo en Durban pese a sus contradicciones» de la Agencia EFE en Sudáfrica, a 28 de noviembre 2011:

http://www.antena3.com/especiales/noticias/ciencia/hazte-eco/-noticias/empiezacumbre-clima-durban_2011112800042.html

84 Véase la «Resolución del Parlamento Europeo sobre la Conferencia sobre el Cambio Climático de Doha» (Qatar) (COP 18):

http://www.europarl.europa.eu/sides/getDoc.do?type=MOTION\&language=ES\&r eference $=$ B7-0496/2012

85 En el DOCE C 376 de 22 de diciembre de 2011 se recoge dicho dictamen, y en él se expone que en enero de 2011 y de conformidad con el artículo 262 del TFUE, la Comisión Europea había decidido consultar al Comité Económico y Social Europeo sobre este tema, y que el Comité había llegado a algunas conclusiones, en especial, tras la primavera árabe vivida por parte de nuestros vecinos del sur del Mediterráneo. Así, al respecto de las energías renovables, se incentiva en especial la energía solar y se reconoce que la mejora de la eficiencia energética es un complemento indispensable del desarrollo de las energías renovables. Afortunadamente, se estimula el que haya planes prácticos claros y responsables, adoptando sobre todo, un planteamiento común y transparente en cuestiones de transferencia de tecnología. 
sector medioambiental fue calificado por la Unión como un sector valiosísimo para activar la economía europea. En este sentido, conviene destacar que en la legislación comunitaria se recogen frases ilustrativas al respecto: «El medio ambiente es una prioridad política de primer orden. Una política transversal que puede ayudar a la Unión Europea a salir de la crisis económica y financiera mundial que azotó el continente europeo en 2008, sentando las bases para un crecimiento con baja intensidad de carbono y reforzando la eficiencia energética» ${ }^{86}$.

Desde mi visión personal, aunque relativizada por mi inquietud medioambiental, no puedo sino esperar que en los próximos meses una nueva razón se imponga y comprendamos nuevamente que las energías renovables son una ayuda imprescindible para frenar el CC. Las energías limpias también han de ser las favorecedoras de un desarrollo económico, tan deseado en estos momentos. Por ello, no puedo finalizar sin hacer mención de la Comunicación de la Comisión al Parlamento Europeo, al Consejo, al Comité Económico y Social Europeo y al Comité de las Regiones, titulada "Energías renovables: principales protagonistas en el mercado europeo de la energía ${ }^{87}$. En la introducción de esta Comunicación se reconoce que «estas energías permiten diversificar el suministro energético, incrementando la seguridad de abastecimiento, creando nuevas industrias, puestos de trabajo, crecimiento económico y oportunidades de exportación, reduciendo al mismo tiempo nuestras emisiones de gases de efecto invernadero.» Por tales afirmaciones, me atrevo a declarar una renovada confianza en los criterios de la UE y en la colaboración necesaria presente y futura -en este ámbito medioambiental- entre la Unión y los EEMM.

86 Consúltese: http://europa.eu/legislation_summaries/environment/general_provisions/ev0016_es.htm final:

Comunicación publicada en Bruselas el 6 de junio de 2012: COM (2012) 271

http://eur-lex.europa.eu/LexUriServ/LexUriServ.do?uri=COM:2012:0271: FIN:ES:PDF 